\title{
The impact of ignition delay and further fuel properties on combustion and emissions in a compression ignition engine
}

\author{
Aydek Gökçe Erman, Paul Hellier, Nicos Ladommatos
}

\section{Department of Mechanical Engineering, University College London, Torrington Place, London WC1E 7JE, United Kingdom}

Received 2 August 2018, Revised 30 August 2019, Accepted 4 September 2019, Published in: Fuel, Volume 262, 15 February 2020, 116155. Available online from 24 October 2019 https://doi.org/10.1016/j.fuel.2019.116155

\begin{abstract}
Better understanding of combustion and formation of exhaust gas pollutants of fuels is needed in order to meet stringent regulation standards of a diesel engine. The cetane number is one of the mostcited indicators of diesel fuel quality. This paper presents experimental studies with a wide range of fuels to investigate the effect of cetane number on combustion and exhaust emissions $\left(\mathrm{CO}, \mathrm{NO}_{\mathrm{x}}, \mathrm{PM}\right.$, particle number size distribution). The fuel ignitability was controlled in two different ways: naturally, by using seven fuels (Dearomatised Hydrotreated Stream, Hydrotreated Non-Dearomatised Stream, Soy Methyl Ester, Rapeseed Methyl Ester, Heavy Paraffinic Stream, C10-C14 Paraffins, and C14-C17 Paraffins) with different cetane numbers, and through the use of an ignition improver blended into a single base fuel (Hydrotreated Non-Dearomatised Stream (NDH)) to change the ignition chemistry of the fuel while keeping physical properties unchanged. The tests were performed in naturally-aspirated single-cylinder DI diesel engine at $1200 \mathrm{rpm}$ and 600 bar injection pressure at 4 bar and 6 bar IMEP. The engine tests were carried out at constant fuel injection timing and constant start of combustion timing. A strong positive correlation was found between ignition delay and $\mathrm{CO}$ emissions. The effect of physical and chemical properties of the fuel on $\mathrm{NO}_{\mathrm{x}}$ and particulate emissions became more dominant at higher load. Overall the results showed that changes in the fuel physical properties and molecular structure, in particular, the incorporation of oxygen, impacted on combustion and emissions through various routes in addition to the effects of ignition delay only.
\end{abstract}

\section{INTRODUCTION}

The diesel engine has traditionally been considered as an attractive automobile power source due to its high thermal efficiency. On the other hand, there is a trade-off between fuel efficiency and exhaust pollutant emissions. Large concentrations of chemical compounds such as oxides of nitrogen, unburned hydrocarbons and carbon monoxide, and global greenhouse emissions, like carbon dioxide, 
are emitted into the atmosphere by vehicles which are major emission source for air pollution [1]. Since these pollutant emissions sources have health, environmental and economic impacts, a reduction in these pollutants would be valuable. The permissible amount of emissions is determined by regulations, and each successive regulation becomes stricter to limit the polluting species from vehicle tailpipes. In these regards, the control of diesel fuel properties is needed for reducing emissions of regulated pollutants. Of the various diesel fuel properties, one of the most-cited indicators of diesel fuel quality is cetane number. Cetane number of fuel can be changed in a variety of ways. Previous studies in the literature have mostly concentrated on methods using singlecomponent fuels [2,3] or a narrow range of fuels [4] or comparing different methods but in the investigation of just one type of exhaust pollutant [5]. Therefore, a comparison between the ways and a better understanding of their correlation between combustion characteristics and the formation of exhaust gas emissions $\left(\mathrm{NO}_{\mathrm{x}}\right.$, particulates and $\left.\mathrm{CO}\right)$ is required to achieve exhaust emission targets.

Investigations have been carried out on different approaches for improving exhaust emissions when alternative fuels are used. From previous studies, it is known that the reductions in aromatics, distillation temperature, viscosity, and density lead to lower particulate matter (PM) emissions [6-10]. Wu et al. [11] found in their studies that the lower viscosity, the higher vapour pressure and the lower boiling point of the tested fuel (dimethyl carbonate) compared to the fossil diesel fuel could improve the fuel atomisation. The improved atomisation could have contributed to the lower particle number and the lower size distribution in the exhaust gas. Nakatita et al. [7] investigated PM formation tendency of fully blended diesel fuels with molecules which were representative of the paraffin molecular classes by examining combustion characteristics and in-cylinder phenomena such as fuelair mixture formation, flame development, and soot formation processes in two types of singlecylinder high-speed direct-injection (HSDI) diesel engines and two optically accessible singlecylinder diesel engines. They found that cycloparaffins had a higher PM formation tendency than isoparaffins and n-paraffins under low and medium loads. They also observed that aromatics had higher PM formation tendency than paraffinic fuels under medium and high load conditions. Nishimu et al. [8] found similar results that aromatic-free fuel was shown to reduce PM emissions further. Zannis et al. [12] conducted experiments in conventional diesel engines, and they reported that reductions of soot, $\mathrm{NO}$ and $\mathrm{CO}$ emissions could be achieved with the reduction of distillation temperature and an increase of paraffin/naphthene ratio.

Many studies have shown that pure biodiesel and biodiesel/diesel blends reduce emissions of regulated emissions such as $\mathrm{PM}$, carbon monoxide $(\mathrm{CO})$ and hydrocarbons $(\mathrm{HC})$ but increase $\mathrm{NO}_{\mathrm{x}}[5$, 13-16]. Hwang et al. [17] tested waste cooking oil biodiesel (WCO) and commercial diesel on a single-cylinder common-rail direct injection diesel engine and found that biodiesel had benefits in reduction of smoke, $\mathrm{CO}$ and $\mathrm{HC}$ emissions, while $\mathrm{NO}_{\mathrm{x}}$ emission increased with WCO under all experimental conditions. Cheng et al. [18] conducted experiments in an optically accessible diesel engine by using two pure hydrocarbon fuels and neat, soy-derived biodiesel. They also observed that $\mathrm{NO}_{\mathrm{x}}$ emissions were increased dramatically as oxygen mole fractions were increased while the soot 
formations were suppressed. The effect on $\mathrm{NO}_{\mathrm{x}}$ emissions of esterified fuels was investigated by Ban-Weiss et al. [19] through a numerical study. They demonstrated with a numerical model that the molecules with unsaturated alkyl chains due to double-bond had higher adiabatic flame temperature and higher $\mathrm{NO}_{\mathrm{x}}$ emission relative to their single-bonded counterparts. They suggested that the increase in $\mathrm{NO}_{\mathrm{x}}$ level was not only driven by a thermal mechanism, but also the molecules with double-bond in their alkyl chains caused higher levels of hydrocarbon radicals in the fuel-rich zone of the diesel spray, increasing the formation of prompt $\mathrm{NO}_{\mathrm{x}}$. Schönborn et al. [20] conducted experiments with different types of fuel samples as fatty acid methyl and alkyl esters to investigate the effects of molecular structures (such as fatty acid chain length, degree of unsaturation and alcohol chain length) on engine combustion and emissions. They found that longer chain molecules burned with shorter ignition delay, which led to less heat release and less $\mathrm{NO}_{\mathrm{x}}$ formation. The longest fatty acid ester (behenic acid methyl ester - 22 carbon atoms) produced the largest amount of particulate mass because of its high viscosity and poor atomisation. It was deduced from the experiments that $\mathrm{NO}_{\mathrm{x}}$ emission was primarily determined by ignition delay, while adiabatic flame temperature played a secondary role. Not only the higher amounts of $\mathrm{NO}_{\mathrm{x}}$ emissions but also higher amounts of particulate emission were observed when the number of double bonds in alkyl chain was increasing, even though the longer delay was expected to lead to better fuel-air mixing and a reduction in soot formation. It was speculated that the dominant effect in soot formation could have been the higher degree of unsaturation due to the double bonds. Double bonds were likely to provide a direct path to the formation of precursors of soot such as ethane and ethyne (acetylene). Mueller et al. [21] tested two biodiesel fuels (B100 and B94) and two alkane reference fuels with different cetane numbers (CN45 and CN70), to understand the relation between $\mathrm{NO}_{\mathrm{x}}$ formation and fuel structure. They used spatially integrated natural luminosity (SINL) to estimate the amount of radiative heat transfer from the reacting in-cylinder mixtures. They suggested that lower radiative heat transfer yielded higher actual flame temperatures and higher thermal $\mathrm{NO}_{\mathrm{x}}$ emissions, and this reason was sufficient to explain why the B94 had lower $\mathrm{NO}_{\mathrm{x}}$ emission than B100. However, pure alkane fuel of cetane number 45 had a level of radiative heat transfer between these two biodiesel blends (B94 and B100), and it produced significantly lower $\mathrm{NO}_{\mathrm{x}}$ emissions than both of them, thereby a further explanation was needed for this phenomenon. Start of combustion (SOC) and ignition delay (ID) were almost constant for all fuels, but the end of premixed burn (EOPMB) occurred earlier for biodiesel blends at both engine loads. The earlier end of premixed burn suggested that the biodiesel blends had faster premixed burning. The faster premixed combustion of the biodiesel blends was expected to result in higher in-cylinder temperature, leading to higher $\mathrm{NO}_{\mathrm{x}}$ emissions than pure alkanes of $\mathrm{CN} 45$, especially at low load. McEnally et al. [22] measured sooting tendencies of 186 oxygenated and 89 regular hydrocarbons by doping these compounds at a rate of $1000 \mathrm{ppm}$ into the fuel of a laboratoryscale burner. Their measurements showed that the sooting tendencies of esters were highly dependent on molecular structure and increased in this order: methyl and ethyl esters < carboxylic acids, propyl 
esters, and n-alkanes < butyl and pentyl esters. These comparisons show that the fuel composition can change the combustion performance and exhaust emission significantly.

The impacts of change in cetane number on emissions have also been investigated in several studies by using both fuel additives as well as fuel components which naturally have high cetane number [5]. While the natural cetane rating is largely correlated with other fuel properties, additised cetane rating principally affects the chemistry of ignition and is therefore largely isolated from the effects of physical and chemical properties of the fuel. Longer chains and higher degrees of saturation of biodiesels typically correlate with higher cetane number, which usually results in shorter ignition delays and less $\mathrm{NO}_{\mathrm{x}}$ emission level [23]. Nishiumi et al. [8] conducted tests on conventional direct injection diesel engine by using paraffinic fuels, which were selected to simulate FisherTropsch Diesel (FTD) fuel, to investigate the effects of cetane number and distillation characteristics on engine-out PM emissions. They found that the excessive-high cetane number and short ignition delay characteristics of paraffin led to poor mixing of injected fuel and air in the chamber, which promoted the formation of unburned THC and insoluble organic fraction. Lilik et al. [24] investigated the effects of cetane number by using a common rail turbodiesel engine which was operated in a high-efficiency clean combustion mode. They found that a synthetic fuel, produced in a hightemperature Fischer-Tropsch (HTFT) process with a derived cetane number (DCN) 51, reduced THC and $\mathrm{CO}$ emission by $32 \%$ and $31 \%$, respectively, compared to the diesel fuel with DCN of 45 ; while a synthetic fuel, produced in a low-temperature Fisher-Tropsch (LTFT) process with DCN of 81, was shown to further reduce THC and CO emissions by $80 \%$ and $74 \%$ respectively, compared to the diesel fuel. Cataluna et al. [4] found similar results that higher $\mathrm{CN}$ resulted in higher in-cylinder temperature in the combustion chamber, which in turn increased the oxidation rates and reduced the emission of unburned HC's. Ladommatos et al. [25] conducted experiments in co-operative fuel research (CFR) diesel engine with base diesel and changed its cetane number from 40.2 to 62 by using ignition improver. The aim of the study was to observe the impact of cetane number on emissions by isolating the effects of physical and chemical properties of the fuel. The results showed that $\mathrm{NO}_{\mathrm{x}}$ and unburnt hydrocarbon (UHC) emissions fell progressively while smoke emission was raised with increasing cetane number. Cai et al. [26] used the same method, and they changed the cetane number of $15 \%$ ethanol-diesel blend by adding $0,0.2 \%$ and $0.4 \%$ percentages of cetane number enhancer. They found that $\mathrm{NO}_{\mathrm{x}}$ and smoke emissions reduced when cetane number enhancer was added to the blend.

The impact of fuel molecular structure and cetane number change on combustion characteristics and emissions were widely reported in the literature. Both additised and natural cetane number impact on a fuel's propensity to auto-ignite, and both approaches are used in practice to improve a fuel's autoignition quality. However, change in natural cetane number is also accompanied by a change in the physical properties of the fuel. Therefore, change in natural cetane number can have a much wider impact on combustion characteristics and exhaust emissions than additised cetane alone, even when the two types of fuel have the same cetane number. This study goes further than previous 
studies by conducting a broader and more systematic study which compares energy release as well as the exhaust emissions $\left(\mathrm{CO}, \mathrm{NO}_{\mathrm{x}}\right.$, particulate mass and number) when these two separate methods are used to produce changes in cetane number and ignition delay. For the first set of experiments, the cetane number of a Hydrotreated Non-Dearomatised refinery Stream (NDH) was changed by adding ignition improver (2-EHN). For the second set of experiments, the cetane number of the fuels was changed naturally by using a various type of fuels which were: Dearomatised Hydrotreated Stream (DH), Hydrotreated Non-Dearomatised Stream (NDH), Soy Methyl Ester (SME), Rapeseed Methyl Ester (RME), Heavy Paraffinic Stream (HP), C10-C14 Paraffins (10P) and C14-C17 Paraffins (P). Constant start of injection and constant start of combustion engine tests were performed for both sets of experiments in a single-cylinder naturally aspirated DI diesel engine at $1200 \mathrm{r} / \mathrm{min}$ and $600 \mathrm{bar}$ injection pressure at two different engine loads of 4 bar and 6 bar IMEP.

\subsection{Test System}

All experiments were conducted in a naturally aspirated, 4-stroke, direct injection, and singlecylinder compression ignition engine. The engine specification can be seen from Table 1.

An ultra-low volume fuel system was used for the experiments which allowed small quantities of fuel to be injected through the engine's 7-hole injector [27]. The in-cylinder gas pressure was measured by a piezoelectric high-pressure transducer (Kistler 6056AU38) which was connected to a charge amplifier (Kistler 5011). Temperatures were measured at 17 locations around the engine by K-type thermocouples. The net apparent heat release rate was derived from the measured in-cylinder pressure during post-processing (MATLAB). The model of the heat release from combustion was based on the first law of thermodynamics for a single zone closed system, with some commonly made assumptions: the cylinder contents and their state were uniform throughout the chamber, the heat released from the combustion occurred uniformly in the chamber, and the gas mixture was an ideal gas [28].

The exhaust gas emissions were measured using a Horiba MEXA 9100HEGR gas analyser with sampling points $180 \mathrm{~mm}$ downstream from the exhaust port. The gas sample was collected from the exhaust manifold at a location of approximately $200 \mathrm{~mm}$ downstream of the exhaust valves of the engine. The particle size distribution (10 to $1000 \mathrm{~nm})$ and number/mass concentrations were measured by a differential mobility particle-size spectrometer (Cambustion DMS500). DMS500 calculates the mass concentration by using a size/number distribution [29]. This calculation assumes that the particles are fractal, i.e. the particles are not perfectly spherical and that the density is uniform, irrespective of particle size [30].

\subsection{Fuel Investigated}

Seven fuels with different cetane number were studied experimentally for this study: Dearomatised Hydrotrreated Stream (DH), Hydrotreated Non-Dearomatised Stream (NDH), Soy 
Methyl Ester (SME), Rapeseed Methyl Ester (RME), Heavy Paraffinic Stream (HP), C10-C14 Paraffins (10P) and C14-C17 Paraffins (P). Table 2 shows the properties of the fuels [31].

The hydrotreated non-dearomatised (NDH) fuel served as the baseline fuel in this study. It has a low cetane number and the highest aromatic content compared to the other six fuels; the other six fuels had none or very little amount of aromatics as $0.2 \% \mathrm{~m} / \mathrm{m}$. The blend of $\mathrm{C} 14-\mathrm{C} 17$ paraffins $(\mathrm{P})$ had the highest cetane number, whereas the dearomatised hydrotreated fuel (DH) had the lowest number. Soy methyl ester (SME) and rapeseed methyl ester (RME) had the highest densities of $0.8849 \mathrm{~kg} / \mathrm{L}$ and $0.8831 \mathrm{~kg} / \mathrm{L}$, respectively. The heavy paraffinic fuel (HP) had the highest viscosity $(7.5 \mathrm{cSt})$ and the highest $\mathrm{T} 90$ temperature $\left(359^{\circ} \mathrm{C}\right)$.

\subsection{Experimental Conditions}

To understand the effect of ignition delay on combustion phasing and emission production, two different sets of tests were conducted. The first set used a single fuel, having constant molecular structure, and its cetane number changed by the addition of ignition improver. The second set used a number of refinery streams and biodiesels, having different molecular structures and cetane numbers. Specifically, the fuels were:

(1)A hydrotreated Non-Dearomatised Stream (NDH) where its ignition delay shortened progressively using cetane number improver.

(2)Different fuels, which had different cetane numbers, were used without cetane improver. This set of experiments was referred to as refinery streams and biodiesels or seven fuels with different cetane numbers $(\mathrm{CN})$.

In the first set of experiments, only the hydrotreated non-dearomatised stream (NDH) was tested and the duration of its ignition delay was changed by adding different amounts of 2-ethylhexyl nitrate (2-EHN) in gradually increasing volume fractions $(0 \%, 0.2 \%, 0.25 \%, 0.5 \%, 1.0 \%, 2.0 \%$ and $2.8 \%)$ and then the additised NDH fuels were tested in the engine. In the second set of experiments, seven fuels with different cetane number were tested. Each of these two sets of fuels was subjected to two series of experiments in which the injection timings were as follows:

(1)Constant start of injection (CSOI) at $3{ }^{\circ} \mathrm{CA}$ BTDC for the low load (at 4 bar IMEP) and $5.5{ }^{\circ} \mathrm{CA}$ BTDC for the high load (at 6 bar IMEP).

(2)Repeat at variable start of injection to ensure constant start of combustion (CSOC) at top dead center (TDC) for all fuels.

All engine data in this study were acquired under steady-state operating conditions at an engine speed of $1200 \mathrm{r} / \mathrm{min}$ and at $600 \mathrm{bar}$ fuel injection pressure. The injection duration was adjusted for each fuel so that the engine IMEP was always constant at 4 bar or 6 bar. 


\subsubsection{Injection Timing Optimisation}

The optimum injection timing which maximised IMEP was investigated for two of the fuels, the hydrotreated non-dearomatised (NDH) and C10-C14 paraffins (10P) fuels at two different loads (4 bar and 6 bar IMEP). Ignition delay durations for these two fuels were substantially different, due to the large difference between their cetane numbers of 46.9 for $\mathrm{NDH}$ and 74.8 for $10 \mathrm{P}$. This optimisation exercise helped answer the question of how the ignition delay duration affected the optimum injection timing, and it also identified the optimum timing that maximise IMEP.

At low load condition of 4 bar IMEP, the injection timing sweep was between $5.5^{\circ} \mathrm{CA}$ BTDC and $1{ }^{\circ} \mathrm{CA}$ BTDC. For the NDH fuel, the lowest IMEP value occurred at $4.5{ }^{\circ} \mathrm{CA}$ TDC; the peak IMEP value was $0.9 \%$ higher than the lowest IMEP, and it occurred at $3{ }^{\circ} \mathrm{CA}$ BTDC. For the $10 \mathrm{P}$ fuel, the lowest IMEP occurred at $5.5{ }^{\circ} \mathrm{CA}$ BTDC while the highest IMEP occurred at $3.5{ }^{\circ} \mathrm{CA}$ BTDC. The IMEP difference between the highest and the lowest values was $0.68 \%$ of the maximum IMEP recorded for the 10P injection timing sweep. The corresponding injection timing sweep at the high load of 6 bar was between $7{ }^{\circ} \mathrm{CA}$ BTDC and $2.5^{\circ} \mathrm{CA}$ BTDC, and maximum IMEP occurred at $5.5{ }^{\circ} \mathrm{CA}$ for both fuels.

These results showed that even though NDH and 10P had substantially different ignition delay durations, the injection timings that maximise IMEP were not very different from each other. As a result, $3{ }^{\circ} \mathrm{CA}$ BTDC at low load of 4 bar and $5.5^{\circ} \mathrm{CA}$ BTDC at high load of 6 bar were selected as the standard injection timings for all subsequent experiments; that as, for (a) the experimental set of NDH with cetane number improver and for (b) the experimental set which used the rest of the fuels with naturally varying cetane number. These selected injection timings generate CA50 timing around $7-10{ }^{\circ} \mathrm{CA}$ ATDC, which is the timing of half of the injected fuel burnt [28].

\subsubsection{Cetane Number Estimation}

All the refinery streams and biodiesels included information on cetane number, which was obtained using the standard procedure on a CFR engine [32]. Cetane number was not available for the blends with ignition improver. In order to provide the reader with an indication of cetane number for these latter fuel blends, their cetane numbers were estimated using the ignition delays and known cetane number information of the fuels. The ignition delays for the fuels were regressed with their cetane numbers, and this resulted in the following curve fit: $y=250.5 \mathrm{e}^{-0.2795 x}\left(\mathrm{R}^{2}=0.72\right)$ where $\mathrm{y}$ was cetane numbers $(\mathrm{CN})$ and $\mathrm{x}$ was the ignition delays (ID) for the refinery streams and biodiesels. Using this expression, and the ID for the NDH plus cetane improver, an indicative estimate of the cetane number for the NDH blends can be obtained ( 4 bar IMEP and 6 bar IMEP).

\section{RESULTS AND DISCUSSION}

\subsection{Combustion Characteristics}

\subsubsection{In-Cylinder Pressure Analysis}


Table 3 and Table 4 showed that, in general, decreased ignition delay period resulted in lower maximum in-cylinder pressure and lower calculated maximum in-cylinder temperature, at both timing conditions (CSOI and CSOC) and loads for both sets of experiments (the set of NDH with ignition improver and the set of refinery streams and biodiesels). The peak in-cylinder pressure was related to the amount of prepared fuel during the ignition delay period, which, in turn, was influenced by the chemical and physical properties of the fuel (Table 3 and Table 4) [17].

Figure 1 to Figure 4 and Table 3 and Table 4 showed that the maximum recorded in-cylinder pressure and maximum calculated temperature were influenced substantially by injection timing. For example, at the low load of 4 bar IMEP, the late constant injection timing caused some of the fuels to burn during the expansion stroke and, as a consequence, the maximum pressure and temperature was lower than for start of combustion at TDC (Table 3 and Table 4). At high load of 6 bar IMEP, the conditions were different, resulting in the start of injection being earlier at $5.5^{\circ} \mathrm{CA}$ BTDC, and as a result, maximum pressure and temperature were higher for the constant start of injection than those for constant start of combustion at TDC.

At higher load, more fuel was delivered so as to obtain higher engine load. Due to the greater amount of fuel injected, the maximum in-cylinder pressure and the calculated maximum temperature were higher than those for low load for both sets of CSOI and CSOC experiments (Table 3 and Table 4).

For the heavy paraffinic fuel (HP), the peak in-cylinder pressure and maximum in-cylinder global temperature were the lowest values in comparison with all the other fuels, at both timings and loads. This can be attributed to the deterioration of fuel-air mixture preparation due to the high viscosity of this fuel [6].

\subsubsection{Heat Release Rates and Premixed Burn Fraction Analysis}

At low load (4 bar IMEP), pronounced high peaks can be observed in apparent heat release rate for the set of NDH with cetane number improver (Figure 5 and Figure 6) as well as for the set of refinery streams and biodiesels (Figure 7 and Figure 8). This suggests that corresponding to all the fuels were consumed predominantly by premixed combustion followed by a long, low level, heat release tail diffusion-controlled combustion [33]. At high load (6 bar IMEP), the converse was observed, and the higher fuel injection durations led to predominantly diffusion combustion, resulting in lower peak heat release rates with double peaks due to shorter ignition delay periods and reduced amount of premixed combustion. Furthermore, with decreasing ignition delay periods; the fraction of diffusion burn was increased further, which led to more pronounced double peak heat release profiles (Figure 5-Figure 8). In general, at CSOI tests $\left(3{ }^{\circ} \mathrm{CA}\right.$ BTDC at 4 bar IMEP and $5.5{ }^{\circ} \mathrm{CA}$ BTDC at 6 bar IMEP) variation of ignition delay significantly changed the heat release rate profile. That is, prolonged ignition delay period led to later start of combustion (SOC) but higher and narrower heat release peak due to increased premixed combustion. It can be seen from Figure 6 and Figure 8 that with start of combustion at TDC (CSOC), the heat release profiles were greatly influenced by varying 
fuel ignition quality because the variations caused changes in the start of injection (SOI) to keep the start of combustion at TDC.

At low load (4 bar IMEP), the ignition delay period for both fixed injection and fixed combustion timings were almost identical and, as a result, injection timing was the dominant effect, more so than the duration of ignition delay. All the injection timings for the constant ignition timing tests were more advanced than $3{ }^{\circ} \mathrm{CA}$ BTDC (Table 3 and Table 4), leading to the increased peak heat release rates. Increasing of peak heat release rate with the advance of injection timing could be attributed to the greater amount of premixed combustion (Table 3 and Table 4), which resulted in short and rapid combustion with a higher rate of heat release [34].

At high load (6 bar IMEP), the ignition delays in the case of constant injection timing were slightly longer than those for constant ignition timing, which resulted in higher peak heat release rates at CSOI (Table 3 and Table 4). The longer ignition delays also led to higher combustion rate and increased premixed combustion (Table 3 and Table 4).

In general, premixed combustion dominated at low load, resulting in higher peak heat release rates, whereas diffusion combustion dominated at high load, leading to lower peak heat release rates.

\subsection{Emission Analysis}

\subsubsection{CO Emissions}

Figure 9 and Figure 10 showed that as the ignition delay period increased, the emission of CO also increased at both timings and both loads, although this effect was more pronounced for the low load of 4 bar IMEP for both sets of timings.

At low load, CO concentration was found to be higher at CSOI timing than at CSOC timing. Retarding of injection timing to $3{ }^{\circ} \mathrm{CA}$ BTDC (at constant injection timing) resulted in the later start of combustion in the case of NDH with cetane number improver and in the case of the set of different fuel streams. This resulted in more of combustion occurring in the expansion stroke, causing the CO oxidation kinetics to be quenched while $\mathrm{CO}$ concentration was still high [35]. In general, $\mathrm{CO}$ emission became lower as the ignition delay period shortened. NDH 2.89\% (v/v) at CSOI and CSOC, $10 \mathrm{P}$ and $\mathrm{P}$ at CSOI and CSOC had the same level of CO concentration, even though the injection timing for CSOC was more advanced than CSOI tests. This can be attributed to the decreased injection timing differences between CSOI and CSOC experiments with the shortened duration of ignition delay (Table 3 and Table 4). Another reason could be related to the exponential relation of ignition delay and temperature, where a small difference in ignition delay could represent a substantial difference in local reaction temperature and CO formation [36].

At high load, the tests with NDH and ignition improver did not show great differences in $\mathrm{CO}$ concentration between fixed injection and fixed ignition timings in Figure 9. This is due to higher incylinder temperatures and shorter ignition delay periods than in the case of low load (Table 3). The set of experiments with the refinery fuel streams and biodiesels showed lower CO concentration for fixed injection timing (Figure 10) due to higher premixed fuel fraction and shorter combustion 
duration (Table 4). In general, it appeared that at high load molecular fuel structural effects were more pronounced, which weakened the correlation between ignition delay and $\mathrm{CO}$ emission formation. This may be because physical properties play a greater role during diffusion combustion and thus affect $\mathrm{CO}$ formation, in addition to the effect of ignition delay on CO. For example, the high viscosity heavy paraffinic fuel (HP) can be expected to cause poor atomisation and fuel distribution in the combustion chamber, which resulted in more incomplete combustion and high CO formation; the impact of physical fuel properties of HP on mixture preparation may be greater than that of ignition delay [37]. Furthermore, fuel molecular structure and the consequent differences in cetane number resulted in a larger impact on $\mathrm{CO}$ emission than NDH with ignition improver additive did.

CO emissions decreased with increasing engine load (Figure 9 and Figure 10). This can be attributed to higher in-cylinder gas temperatures and a slight reduction in ignition delay at higher engine load, which caused more efficient combustion of fuel and reduction of fuel over-dilution, respectively.

\subsection{2. $\mathrm{NO}_{\mathrm{x}}$ Emissions}

At low load (4 bar IMEP), advanced fuel injection timing and longer ignition delay led to higher $\mathrm{NO}_{\mathrm{x}}$ emissions for both sets of experiments involving the set of the refinery streams and biodiesels as well as the set of NDH with ignition improver. At low load and with constant start of ignition (CSOC) at TDC, the $\mathrm{NO}_{\mathrm{x}}$ emissions were generally higher by about $10 \%$ than those at constant start of injection (CSOI) for both sets of fuels (Figure 11 and Figure 12). This could be ascribed to earlier start of injection timings required for CSOC, which caused earlier start of combustion before top dead center (Table 3 and Table 4) and longer residence time, which led to higher maximum in-cylinder temperatures and greater $\mathrm{NO}_{\mathrm{x}}$ formation. Moreover, increased ignition delay duration was additional reason for higher $\mathrm{NO}_{\mathrm{x}}$ emissions (Table 3 and Table 4). At low load, a strong correlation between maximum in-cylinder temperature and ignition delay duration was observed for both sets of experiments (NDH plus improver as well as refinery streams and biodiesels) at both timing conditions (CSOI and CSOC). This could be attributed to higher in-cylinder pressures with longer ignition delay durations, which led to higher in-cylinder temperatures.

At high load (6 bar IMEP), advanced injection timing affected $\mathrm{NO}_{\mathrm{x}}$ formation greatly. Also, $\mathrm{NO}_{\mathrm{x}}$ emissions became more sensitive to changes in physical and chemical properties of the fuels (Figure 12 and Figure 14). First of all, the results at high load showed that with CSOI, $\mathrm{NO}_{\mathrm{x}}$ emissions were higher than with CSOC due to advanced injection timings with CSOI. That is for both the fuel sets of NDH with cetane improver and seven fuels with different $\mathrm{CN}$; the calculated maximum incylinder temperatures were higher with CSOI at $5.5{ }^{\circ} \mathrm{CA}$ BTDC (Figure 11 and Figure 12). Moreover, the correlation between $\mathrm{NO}_{\mathrm{x}}$ and ignition delay was poorer at high load than at low load, which was showing greater scatter at high load (Figure 13 and Figure 14). This was thought to be due to more pronounced effects of physical fuel properties on $\mathrm{NO}_{\mathrm{x}}$ formation (Figure 12 and Figure 14) at high load. This suggests that ignition delay alone could not be responsible for the difference in $\mathrm{NO}_{\mathrm{x}}$ 
emissions with engine load. At high load, the $\mathrm{NO}_{\mathrm{x}}$ differences of $\mathrm{RME}$ and SME were greatly increased for both timings. The increase in $\mathrm{NO}_{\mathrm{x}}$ for the two FAME (RME and SME) was mainly due to higher combustion temperature, which may have resulted in their oxygen content making more oxidant available in the spray core [15]. In addition to their oxygen content, their higher densities could also have resulted in better fuel-air mixing as a result of longer spray penetration before evaporation and, therefore, led to an increase in air entrainment in the spray [38]. It can be observed from Figure 12 that SME reached the highest maximum in-cylinder combustion temperature earlier than the other fuels (Table 4), which resulted in a longer duration of available time at high temperature for $\mathrm{NO}_{\mathrm{x}}$ formation. On the other hand, the maximum in-cylinder temperature was the lowest and occurred latest for the heavy paraffinic (HP) stream, which had the lowest $\mathrm{NO}_{\mathrm{x}}$ emissions for both timing conditions and loads. For HP, the peak in-cylinder pressure and calculated maximum in-cylinder global temperature (Figure 12) were the lowest for both timings and both load conditions, and this is believed to have been due to deterioration of fuel-air mixture preparation as a result of high viscosity [6]. Generally, $\mathrm{NO}_{\mathrm{x}}$ emissions tend to decrease as radiative heat transfer from incylinder soot particles increases, by limiting peak flame temperatures and prolonging combustion event. Due to high cetane number and viscosity of heavy paraffinic stream (HP), it had the highest amount of particulate mass and the lowest amount of $\mathrm{NO}_{\mathrm{x}}$ emission (Figure 22) for both timing conditions (CSOI and CSOC) and loads (4 bar and 6 bar IMEP). The difference was significant compared with the other six fuels which had lower viscosities and the lower amount of particulate mass.

Considering the above results as a whole, it can be concluding that increasing cetane number in two ways, through ignition improver and through fuels with different cetane numbers, produced different impact on combustion and emissions. At both 4 and 6 bar IMEP, the in-cylinder temperatures of NDH with additive did not generally show sensitivity to ignition delay (except NDH $0 \%(\mathrm{v} / \mathrm{v}))$ when the fuels were injected at constant injection timing $\left(3{ }^{\circ} \mathrm{CA}\right.$ BTDC at low load and 5.5 ${ }^{\circ} \mathrm{CA}$ BTDC at high load) (Figure 11 and Figure 13). However, the set of experiments with seven fuels with different $\mathrm{CN}$ showed greater sensitivity of cylinder gas temperature to ignition delay at CSOI and 4 bar IMEP (Figure 12 and Figure 14). The reason of flat behaviour of the NDH blends could be that as the ignition delay of the blends was reduced through the addition of 2-EHN, the level of fuel bound nitrogen, and thus the potential for $\mathrm{NO}_{\mathrm{x}}$ formation from fuel bound nitrogen, increased significantly up to a maximum level of $2.9 \%$ 2-EHN. Therefore, it is suggested that a similar trend of increasing $\mathrm{NO}_{\mathrm{x}}$ emissions with increasing maximum in-cylinder temperature is not apparent in the case of the NDH blends due to the elevated levels of $\mathrm{NO}_{\mathrm{x}}$ formation attributable to the presence of 2EHN in the case of blends with shorter ignition delays (and lower in-cylinder temperatures).

As expected, at high engine load, more fuel was injected which led to the generation of higher combustion temperatures and $\mathrm{NO}_{\mathrm{x}}$ emissions than low engine load for both the fuel sets (Figure 11 to Figure 14). 


\subsubsection{Particulate Emission Analysis}

The particle size distribution for the various fuels includes two modes: the nucleation mode, which covers the particle range up to $50 \mathrm{~nm}$ and the accumulation mode, which covers the range above $50 \mathrm{~nm}$ [39]. The nucleation mode is composed mainly of volatile organic and sulfur compounds which are formed during exhaust dilution and cooling and originate from the condensation of fuel/oil, or due to incomplete pyrolysis of fuel/oil [40, 41]. The accumulation mode mainly consists of carbonaceous agglomerates and material adsorbed on the agglomerates. The main source of the carbonaceous fraction of the agglomerates is pyrolytic products formed by fuel-rich combustion, which occurs mainly in the fuel spray core [40, 41].

In this study, the nucleation mode was considered to have particles with a mean geometric diameter ranging from 10 to $50 \mathrm{~nm}$, while the accumulation mode included geometric mean diameters ranging from $50 \mathrm{~nm}$ to $1000 \mathrm{~nm}$.

\subsubsection{Particle Number Concentration Analysis}

At low load, in the case of both experimental sets, prolonged ignition delay appeared to have caused the number of particles in nucleation mode $\left(10 \mathrm{~nm}<\mathrm{D}_{\mathrm{p}}<50 \mathrm{~nm}\right.$ ) (Figure 15 and Figure 17) to increase, and this was coupled with a decrease in accumulation mode particles $\left(50 \mathrm{~nm}<\mathrm{D}_{\mathrm{p}}<1000\right.$ $\mathrm{nm}$ ) for both injection and combustion timing conditions (Figure 16 and Figure 18). Therefore, it can be said that prolonged ignition delay was effective in decreasing the accumulation mode particles, while the nucleation mode particles became more numerous. It is possible that, with longer ignition delay, the concentration of accumulation mode soot particles diminished, resulting in the less available surface area for volatile material to be adsorbed on; in turn, this could have favoured nucleation of new particles, rather than adsorption onto existing particles [42]. Therefore, at low load, longer ignition delay appears to significantly improve the total particulate mass, by lowering accumulation mode particle concentration, but increased particle number concentration by increasing the number of particles with low aerodynamic diameters $\left(D_{p}<50 \mathrm{~nm}\right)$. It has been reported that the risk of toxicity to human health increases with smaller particle size, with nanometer-size particles being more dangerous than micron size particles as they can penetrate deeper into the human pulmonary system $[39,43]$. As a result, prolonged ignition delay can help decrease the accumulation mode particulate number through better mixture preparation and soot precursor oxidation, but it cannot achieve complete removal of particles; thereby, the toxicity risk of the remaining particles increases $[44,45]$.

At high load, for NDH with ignition additive, the trend was different to that at low load, and prolonged ignition delay caused the number of nucleation mode particles (Figure 15) as well as the number of accumulation mode particles to increase (Figure 16).

At high load, for the refinery streams and biodiesels set, it is considerably harder to explain the relations between ignition delay and the number of particles in accumulation mode due to substantial data scatter (Figure 18). A possible reason for this is that particle size is not only affected 
by ignition delay or injection strategy, but it may also be influenced substantially by molecular structure and the physical properties of the fuels. With the 6 bar tests, SME and RME had the highest number of nucleation mode particles which could be due to the presence of more volatile PM [42, 46]. In the case of the HP stream, it had the highest number of accumulation mode particles, and it was independent of its ignition delay durations.

For both NDH with improver and the set of various fuels, at high load, more soot particles were produced than at low load, and this was likely to be due to increased fuel consumption, higher overall equivalence ratio, and more extended period of diffusion combustion at high temperature (Table 3 and Table 4), which accelerated soot formation and enhanced greater particle growth [47].

\subsubsection{Particle Number Distribution Curves Analysis}

At low load, for both CSOI and CSOC timings, and both fuel sets, the particle size distribution curves changed their shape when the ignition delay period changed (Figure 19).

At low load CSOI, NDH without additive (NDH 0\% (v/v)) exhibited monomodal particle distribution with a steep peak located in the nucleation. As the ignition delay decreased, the shape changed to bimodal distribution with double peaks in both nucleation and accumulation modes. At low load, with decreasing ignition delay, the peaks in nucleation mode particles range declined gradually, while the peaks corresponding to accumulation mode were becoming more pronounced. Considering the results at low load in more detail, the CSOC results for NDH with ignition improver showed bimodal distribution patterns, with the diminishing peaks in nucleation mode and rising peaks in accumulation mode as the ignition delay duration decreased. For the set of experiment with refinery streams and biodiesels at low load CSOI, DH and NDH exhibited monomodal distribution shapes with a steep peak in the nucleation mode. SME, RME, 10P, P and HP, on the other hand, had double peaks, where the peak at accumulation mode became more pronounced with decreasing ignition delay. Considering now the low load CSOC results, DH, NDH and SME showed bimodal distributions with steep peaks in the nucleation mode, whereas the distribution curves for RME, 10P, $\mathrm{P}$ and HP became monomodal with increased ignition delay. The refinery streams and biodiesels at low load showed similar distribution shapes with NDH plus ignition improver, whereby prolonged ignition delay caused the peaks to shift towards accumulation mode.

Considering the results at high load, both fuel sets showed greater accumulation mode particles than at low load and correspondingly fewer nucleation mode particles. At high load, both the set of NDH with ignition improver and the set of seven fuels with different CN showed wellestablished monomodal shapes where the single peaks were in the nucleation mode (Figure 20). With decreasing ignition delay, these peaks gradually shifted towards the accumulation mode for both timings (CSOI and CSOC). The proportion of accumulation mode particles became higher at CSOC for both sets of fuels. This can be seen from Figure 20, where CSOC corresponds to wider particulate distribution than CSOI. Furthermore, at high load, the effects of the fuel molecular structure became 
more dominant for the refinery streams and biodiesels. At 6 bar IMEP and both CSOI and CSOC timings, even though the ignition delay duration of SME was shorter than that for DH and NDH, SME had the highest peak in nucleation mode particles. In addition to that, even though the ignition delay of HP was not the shortest at low and high load, it had the highest proportion in accumulation mode, which can be attributed to the exceptionally high viscosity of HP.

With prolonged ignition delay, the peaks of the particle number distributions shifted towards the nucleation mode, which resulted in decreased particle diameter at both loads. As discussed above, this is expected to have been resulting from a greater proportion of premixed combustion.

\subsubsection{Particulate Mass Analysis}

Particle mass concentration is dominated by the larger accumulation mode even when these particles are much fewer in number than the nucleation ones [17, 41].

At low load, for both sets of fuels, an inverse correlation was found between the duration of ignition delay and particulate mass (Figure 21 and Figure 22) for both injection timing (CSOI and CSOC). It was shown that the prolonged ignition delay led to a decrease in the accumulation mode particles while the nuclei mode particles became dominant (Figure 15 - Figure 18). The dominance of nucleation mode particles, which was accompanied by the reduction of accumulation mode ones, could be one of the reasons for the particulate mass reduction with prolonged ignition delay at 4 bar IMEP [17, 41]. This inverse relation could be attributed to increased ignition delay enhancing fuel-air mixing; thereby, reducing the local equivalence ratio and increasing in-cylinder temperatures (Table 3 and Table 4) both of which helped reduce particulate emission [36].

At high load, for the fuel set of NDH with additive, particulate mass concentration almost had the same trends with the concentration of accumulation mode particles for both timing conditions (Figure 16 and Figure 21). For these experiments, a single fuel (NDH) was used with varying (small) quantities of ignition improver; therefore, while the ignition chemistry varied, the physical properties of the NDH blends with additive were almost unchanged.

At high load, molecular structural effects on particulate emissions became more significant than at low load (Figure 22). For example, high fuel aromatic content, which serves as a precursor for soot formation, had a tendency to increase soot formation and particulate emission. It can be seen from Figure 22 that the aromatic content of the hydrotreated non-dearomatised stream (NDH) tended to offset the reducing effect of long ignition delay period on particulate emissions at high load [22]. Even though C10-C14 paraffins (10P) and C14-C17 paraffins (P) had shorter ignition delay than $\mathrm{NDH}$, their lower particulate mass emission at high load could be attributed to their paraffinic structure which has been shown to reduce PM emissions, compared to aromatics-containing fuels such as NDH [7, 48]. On the other hand, at low load, it can be concluded that aromatic content had only a secondary effect on soot emissions compared to that of prolonged ignition delay period [36]. In the case of the SME and RME fuels, at both timing conditions (CSOI and CSOC), even though 
both fuels had a high concentration of accumulation mode particles (Figure 18), the total number of particles was dominated by nucleation mode ones which suppressed their total particulate mass.

Fuel distillation curves provide information about fuel volatility. For example, a low T10 temperature, for $10 \%$ fuel recovered as vapour, indicates higher fuel volatility. On the other hand, T90, a high temperature of $90 \%$ vapour recovered indicates the presence of non-volatile high molecular weight compounds which could generate particulates due to their poor vaporisation in addition to other chemical effects on the particulate formation (e.g. long carbon chains) [4, 28, 36]. Even though the 10P and P fuels had the shortest duration of ignition delay, due to their lower T90 temperatures and viscosities than RME and SME, both 10P and P generated lower particulate mass at high load for both timing conditions. Therefore, it could be concluded that the shorter ignition delay and less premixed fuel was offset by higher volatility for 10P and P fuels, which speeded up the fuelair mixing rate despite their shorter delay. An additional factor, however, that may complicate this trade-off, between delay and volatility, was the fact that both RME and SME have longer carbon alkyl chains, which include some double bonds, in comparison with $10 \mathrm{P}$ and $\mathrm{P}$, and it is known that longer chains and double bonds increase soot formation [20]. Furthermore, heavy paraffins (HP) generated the highest amount of particulate matter at both loads and for both timings due to their high viscosity. The combination of high viscosity and high cetane number worsened fuel atomisation and curtailed the time available for fuel-air mixing, thus inhibiting the formation of the combustible mixture and causing incomplete combustion [4].

At both loads (4 bar IMEP and 6 bar IMEP), advanced injection timing, and thereby, higher combustion temperatures reduced particulate emission (Figure 23 and Figure 24). This effect was present with both sets of fuels, irrespective of whether the ignition delay was changed by ignition improver or it was changed naturally by using different fuels having different cetane number.

At low load and constant ignition timing (CSOC) at TDC the reverse was the case, with injection timing was more advanced than that for the constant start of injection (CSOI) tests. While at high load, constant start of injection at $5.5^{\circ} \mathrm{CA}$ BTDC having more advanced injection timing than constant start of ignition at TDC. The advanced injection timings raised the temperatures for CSOC at low load and CSOI at high load, and this resulted in lower particulate mass emissions (Figure 23 and Figure 24). When injection timing was more advanced, more time was available close to TDC for fuel-air mixing, and this resulted in higher in-cylinder pressures and higher in-cylinder temperatures (Table 3 and Table 4), which enhanced oxidation and reduced particulate mass emissions [17].

At high engine loads, more fuel was injected which resulted in longer diffusion combustion during, while there was poorer fuel-air mixing than with premixed combustion, leading to higher local equivalence ratio; therefore, a higher absolute mass of particles was produced at higher engine loads [49], for both the fuel sets and at both the timing conditions (Figure 21 and Figure 22). 


\section{CONCLUSIONS}

The impact of cetane number change on combustion characteristics and the exhaust emissions of $\mathrm{CO}, \mathrm{NO}_{\mathrm{x}}, \mathrm{PM}$ and exhaust particle number $(\mathrm{PN})$ was investigated. The cetane number was controlled in two different ways: naturally through a wide range of refinery streams and biodiesels representing commercial diesel fuels, and via the use of an ignition improving additive blended into a single base fuel. Constant start of injection and constant start of combustion tests were performed for both set of experiments in a single-cylinder naturally aspirated DI diesel engine at a constant speed for two different loads with the main findings as follows:

1. At high load, it was found that, in the case of the seven fuels with different CN, ignition delay was not the dominant effect on $\mathrm{NO}_{\mathrm{x}}$ and particulate mass emissions. It was argued that at this condition, physical properties and molecular structure also had a substantial influence on $\mathrm{NO}_{\mathrm{x}}$ and particulates. For example, even though SME did not have the longest duration of ignition delay, but it produced the highest amount of $\mathrm{NO}_{\mathrm{x}}$ emissions which could have been caused by its oxygen content and high density. HP did not have the shortest ignition delay, but it emitted the highest amount of particulate mass and the lowest level of $\mathrm{NO}_{\mathrm{x}}$ at both timing conditions. Its higher amount of particulate mass could have caused a higher amount of heat radiation losses, which in turn resulted in the lowest level of $\mathrm{NO}_{\mathrm{x}}$ emissions.

2. In the case of both fuel sets, prolonged ignition delay appeared to have caused the number of particles in nucleation mode $\left(10 \mathrm{~nm}<\mathrm{D}_{\mathrm{p}}<50 \mathrm{~nm}\right)$ to increase coupled with a corresponding decrease in accumulation mode particles $\left(50 \mathrm{~nm}<\mathrm{D}_{\mathrm{p}}<1000 \mathrm{~nm}\right)$ at 4 bar IMEP for both timings. At 6 bar IMEP and in the case of NDH with varying levels of ignition improving additive, prolonged ignition delay caused an increase in the number of accumulation mode particles. The trend between ignition delay and the number of particles in accumulation mode were less uniform for the refinery streams and biodiesels set, likely attributable to influences of fuel molecule structure.

3. A strong positive correlation was found between ignition delay duration and $\mathrm{CO}$ emissions. For both sets of fuels, $\mathrm{CO}$ emissions increased with increased ignition delay, at both timings and both loads. This behaviour was attributed to the production of over-diluted, and hence over-lean, mixtures due to longer ignition delay, and also quenching of the mixture at cylinder walls. For the refinery streams and biodiesels tested, molecular structural properties had a substantial influence on $\mathrm{CO}$ concentrations at high load.

4. At low load, NDH with additive exhibited a bimodal particle size distribution for both timing conditions (CSOI and CSOC). The exception was NDH $0 \%(\mathrm{v} / \mathrm{v})$ with CSOI, which had a monomodal distribution with a steep peak at nucleation mode. For the set of seven fuels with 
different $\mathrm{CN}$ at low load and CSOI, the particle size distribution was monomodal with the peak at nucleation mode (DH and NDH). However, in the case of fuels with a shorter duration of ignition delay (SME, RME, 10P, P and HP), a bimodal particle size distribution was observed. At CSOC timing and shorter ignition delays, the distribution curves were bimodal for DH, NDH, and SME, but monomodal for RME, 10P, P and HP with the peak at accumulation mode. At high load and with both CSOI and CSOC timings, both sets of fuels showed monomodal particle size distributions, with the peaks in the nucleation mode. In all cases, as the ignition delay decreased, the peak particle number gradually decreased in magnitude and increased in particle diameter towards the accumulation mode.

\section{References}

1. Spleight J. G, O.B., Petroleum Refining Processes. 2001: CRC Press.

2. Hellier, P., N. Ladommatos, R. Allan, and J. Rogerson, Combustion and emissions characteristics of toluene/n-heptane and 1-octene/n-octane binary mixtures in a direct injection compression ignition engine. Combustion and Flame, 2013. 160(10): p. 2141-2158.

3. Hellier, P., N. Ladommatos, R. Allan, and J. Rogerson, Influence of Carbonate Ester Molecular Structure on Compression Ignition Combustion and Emissions. Energy \& Fuels, 2013. 27(9): p. 5222-5245.

4. Cataluna, R. and R. Da Silva, Effect of Cetane Number on Specific Fuel Consumption and Particulate Matter and Unburned Hydrocarbon Emissions from Diesel Engines. Journal of Combustion, 2012. 2012: p. 6.

5. EPA, The Effect of Cetane Number Increase Due to Additives on NOx Emissions from Heavy-Duty Highway Engines. 2003, United States Environmental Protection Agency.

6. Agarwal, A.K., D.K. Srivastava, A. Dhar, R.K. Maurya, P.C. Shukla, and A.P. Singh, Effect of fuel injection timing and pressure on combustion, emissions and performance characteristics of a single cylinder diesel engine. Fuel, 2013. 111: p. 374-383.

7. Nakakita, K., H. Ban, S. Takasu, Y. Hotta, K. Inagaki, W. Weissman, and J.T. Farrell, Effect of Hydrocarbon Molecular Structure in Diesel Fuel on In-Cylinder Soot Formation and Exhaust Emissions. 2003, SAE International.

8. Nishiumi, R., A. Yasuda, Y. Tsukasaki, and T. Tanaka, Effects of Cetane Number and Distillation Characteristics of Paraffinic Diesel Fuels on PM Emission from a DI Diesel Engine. 2004, SAE International.

9. Sienicki, E.J., R.E. Jass, W.J. Slodowske, C.I. McCarthy, and A.L. Krodel, Diesel Fuel Aromatic and Cetane Number Effects on Combustion and Emissions From a Prototype 1991 Diesel Engine. 1990, SAE International.

10.Tanaka, S., M. Morinaga, H. Yoshida, H. Takizawa, K. Sanse, and H. Ikebe, Effects of Fuel Properties on Exhaust Emissions from DI Diesel Engines. 1996, SAE International.

11. Wu, Z., Z. Zhu, and Z. Huang, An experimental study on the spray structure of oxygenated fuel using laserbased visualization and particle image velocimetry. Fuel, 2006. 85(10): p. 1458-1464.

12.Zannis, T.C., D.T. Hountalas, and R.G. Papagiannakis, Experimental Study of Diesel Fuel Effects on Direct Injection (DI) Diesel Engine Performance and Pollutant Emissions. Energy \& Fuels, 2007. 21(5): p. 2642-2654.

13. Cheng, S.W.K.L., D. Y. C, Dynamometer Testing Of In-service Vehicles Using Biodiesel And Ultra Low Sulphur Diesel. WIT Transactions on Ecology and the Environment, 2002. 53.

14.Graboski, M.S. and R.L. McCormick, Combustion of fat and vegetable oil derived fuels in diesel engines. Progress in Energy and Combustion Science, 1998. 24(2): p. 125-164.

15.Johansson, M., J. Yang, R. Ochoterena, S. Gjirja, and I. Denbratt, NOx and soot emissions trends for RME, SME and PME fuels using engine and spray experiments in combination with simulations. Fuel, 2013. 106(Supplement C): p. 293-302.

16. McGill, R., J. Storey, R. Wagner, D. Irick, P. Aakko, M. Westerholm, N.-O. Nylund, and M. Lappi, Emission Performance of Selected Biodiesel Fuels. 2003, SAE International.

17. Hwang, J., D. Qi, Y. Jung, and C. Bae, Effect of injection parameters on the combustion and emission characteristics in a common-rail direct injection diesel engine fueled with waste cooking oil biodiesel. Renewable Energy, 2014. 63: p. 9-17.

18. Cheng, A.S., A. Upatnieks, and C.J. Mueller, Investigation of the impact of biodiesel fuelling on NOx emissions using an optical direct injection diesel engine. International Journal of Engine Research, 2006. 7(4): p. 297-318. 
19. Ban-Weiss, G.A., J.Y. Chen, B.A. Buchholz, and R.W. Dibble, A numerical investigation into the anomalous slight NOx increase when burning biodiesel; A new (old) theory. Fuel Processing Technology, 2007. 88(7): p. 659-667.

20.Schönborn, A., N. Ladommatos, J. Williams, R. Allan, and J. Rogerson, The influence of molecular structure of fatty acid monoalkyl esters on diesel combustion. Combustion and Flame, 2009. 156(7): p. 1396-1412.

21. Mueller, C.J., A.L. Boehman, and G.C. Martin, An Experimental Investigation of the Origin of Increased NOx Emissions When Fueling a Heavy-Duty Compression-Ignition Engine with Soy Biodiesel. SAE Int. J. Fuels Lubr., 2009. 2(1): p. 789-816.

22. McEnally, C.S. and L.D. Pfefferle, Sooting Tendencies of Oxygenated Hydrocarbons in Laboratory-Scale Flames. Environ. Sci. Technol., 2011. 45(6): p. 2498-2503.

23. McCormick, R.L., J.R. Alvarez, M.S. Graboski, K.S. Tyson, and K. Vertin, Fuel Additive and Blending Approaches to Reducing NOx Emissions from Biodiesel. 2002, SAE International.

24.Lilik, G.K. and A.L. Boehman, Advanced Diesel Combustion of a High Cetane Number Fuel with Low Hydrocarbon and Carbon Monoxide Emissions. Energy \& Fuels, 2011. 25(4): p. 1444-1456.

25. Ladommatos, N., M. Parsi, and A. Knowles, The effect of fuel cetane improver on diesel pollutant emissions. Fuel, 1996. 75(1): p. 8-14.

26.Xing-cai, L., Y. Jian-guang, Z. Wu-gao, and $\mathrm{H}$. Zhen, Effect of cetane number improver on heat release rate and emissions of high speed diesel engine fueled with ethanol-diesel blend fuel. Fuel, 2004. 83(14): p. 20132020.

27. Hellier, P.R., The Molecular Structure of Future Fuels, in Mechanical Engineering. 2013, University College London.

28. Heywood, J.B., Internal Combustion Engine Fundamentals. 1988: New York: McGraw-Hill.

29. Real-time Mass Concentrations from Measured Size Distributions. Cambustion.

30. Whelan, I., D. Timoney, W. Smith, and S. Samuel, The Effect of a Three-Way Catalytic Converter on Particulate Matter from a Gasoline Direct-Injection Engine During Cold-Start. SAE Int. J. Engines, 2013. 6(2): p. 1035-1045.

31. Koivisto, E.K. and Koivisto, Ignition and combustion of future oxygenated fuels in compression-ignition engines.

32. Compendium of Experimental Cetane Numbers. 2017, National Renewable Energy Laboratory.

33. Ye, P. and A.L. Boehman, An investigation of the impact of injection strategy and biodiesel on engine NOx and particulate matter emissions with a common-rail turbocharged DI diesel engine. Fuel, 2012. 97(Supplement C): p. 476-488.

34. Bobba, M.K., C.L. Genzale, and M.P.B. Musculus, Effect of Ignition Delay on In-Cylinder Soot Characteristics of a Heavy Duty Diesel Engine Operating at Low Temperature Conditions. SAE Int. J. Engines, 2009. 2(1): p. 911-924.

35. Musculus, M.P.B., T. Lachaux, L.M. Pickett, and C.A. Idicheria, End-of-Injection Over-Mixing and Unburned Hydrocarbon Emissions in Low-Temperature-Combustion Diesel Engines. 2007, SAE International.

36. Sun, C., D. Kang, S.V. Bohac, and A.L. Boehman, Impact of Fuel and Injection Timing on Partially Premixed Charge Compression Ignition Combustion. Energy \& Fuels, 2016. 30(5): p. 4331-4345.

37. Ileri, E., Experimental study of 2-ethylhexyl nitrate effects on engine performance and exhaust emissions of a diesel engine fueled with n-butanol or 1-pentanol diesel-sunflower oil blends. Energy Conversion and Management, 2016. 118(Supplement C): p. 320-330.

38. Kuti, O.A., J. Zhu, K. Nishida, X. Wang, and Z. Huang, Characterization of spray and combustion processes of biodiesel fuel injected by diesel engine common rail system. Fuel, 2013. 104(Supplement C): p. 838-846.

39. Kittelson, D.B., Engines and nanoparticles: a review. Journal of Aerosol Science, 1998. 29(5): p. 575-588.

40. Chen, R., M. Tinsdale, and P. Price, The Impact of Biodiesel on Particle Number, Size and Mass Emissions from a Euro4 Diesel Vehicle. Vol. 3. 2010.

41. Kittelson, D. and M. Kraft, Particle Formation and Models in Internal Combustion Engines. Cambridge Centre for Computational Chemical Engineering, 2014.

42.Jung, H., D.B. Kittelson, and M.R. Zachariah, Characteristics of SME biodiesel-fueled diesel particle emissions and the kinetics of oxidation. Environ Sci Technol, 2006. 40(16): p. 4949-55.

43. Donaldson, K., X.Y. Li, and W. MacNee, Ultrafine (nanometre) particle mediated lung injury. Journal of Aerosol Science, 1998. 29(5): p. 553-560.

44.Kreso, A.M., J.H. Johnson, L.D. Gratz, S.T. Bagley, and D.G. Leddy, A Study of the Effects of Exhaust Gas Recirculation on Heavy-Duty Diesel Engine Emissions. 1998, SAE International.

45. Pagán, J., Study of Particle Size Distributions Emitted by a Diesel Engine. 1999, SAE International. 
46. Puzun, A., S. Wanchen, L. Guoliang, T. Manzhi, L. Chunjie, and C. Shibao, Characteristics of Particle Size Distributions About Emissions in A Common-rail Diesel Engine with Biodiesel Blends. Procedia Environmental Sciences, 2011. 11: p. 1371-1378.

47. Tsolakis, A., Effects on Particle Size Distribution from the Diesel Engine Operating on RME-Biodiesel with EGR. Energy \& Fuels, 2006. 20(4): p. 1418-1424.

48. Alleman, T.L. and R.L. McCormick, Fischer-Tropsch Diesel Fuels - Properties and Exhaust Emissions: A Literature Review. 2003, SAE International.

49. Longfie Chen, S.D., Haoye Liu, Yiji Lu, Yanfei Li, Anthony Paul Roskilly, Comparative study of combustion and emissions of kerosene (RP-3), kerosene-pentanol blends and diesel in a compression ignition engine. Applied Energy, 2017. 203: p. 91-100.

\section{Table 1}

Engine Specification.

Engine head model

Engine crankcase model

Number of cylinders

Cylinder bore

Crankshaft stroke

Swept volume

Compression ratio

Maximum cylinder pressure

Piston bowl design

Minimum engine running speed

Maximum engine running speed Injector

\author{
Ford Duratorq \\ Ricardo Hydra \\ 1 \\ $86 \mathrm{~mm}$ \\ $86 \mathrm{~mm}$ \\ $499.56 \mathrm{cc}$ \\ 18.2:1 \\ 150 bar \\ w-bowl \\ $755 \pm 5 \mathrm{rpm}$ \\ $5500 \pm 50 \mathrm{rpm}$
}

7-hole (DELPHI)

\section{Table 2.}

Fuel Properties.

\begin{tabular}{|c|c|c|c|c|c|c|c|}
\hline Fuels & $\begin{array}{l}\text { Dearomatised } \\
\text { Hydrotreated } \\
\text { Stream (DH) }\end{array}$ & $\begin{array}{l}\text { Hydrotreated } \\
\text { Non- } \\
\text { Dearomatised } \\
\text { Stream } \\
(\mathrm{NDH})\end{array}$ & $\begin{array}{l}\text { Soy Methyl } \\
\text { Ester } \\
\text { (SME) }\end{array}$ & $\begin{array}{l}\text { Rapeseed } \\
\text { Methyl Ester } \\
\text { (RME) }\end{array}$ & $\begin{array}{l}\text { Heavy } \\
\text { Paraffinic } \\
\text { Stream (HP) }\end{array}$ & $\begin{array}{l}\text { C10-C14 } \\
\text { Paraffins } \\
(10 \mathrm{P})\end{array}$ & $\begin{array}{l}\text { C14-C17 } \\
\text { Paraffins (P) }\end{array}$ \\
\hline Cetane Number & 45.9 & 46.9 & 52 & 52 & 67.2 & 74.8 & 75.2 \\
\hline $\begin{array}{l}\mathrm{KV} @ \mathbf{4 0}{ }^{\circ} \mathrm{C} \\
\mathbf{c S t}\end{array}$ & 1.051 & 1.598 & 4.075 & 4.325 & 7.5 & 1.227 & 1.727 \\
\hline Density (kg/L) & 0.7752 & 0.8167 & 0.8849 & 0.8831 & 0.8269 & 0.7449 & 0.7608 \\
\hline $\mathrm{T} 10\left({ }^{\circ} \mathrm{C}\right)$ & 161.9 & 210.8 & 333.1 & 334.5 & 315.6 & 187.5 & 227 \\
\hline T50 $\left({ }^{\circ} \mathrm{C}\right)$ & 170.4 & 218.8 & 334.9 & 335.9 & 338 & 192.4 & 228.5 \\
\hline $\mathrm{T} 90\left({ }^{\circ} \mathrm{C}\right)$ & 183.2 & 231.2 & 345.5 & 343.8 & 359 & 204.7 & 231.6 \\
\hline $\begin{array}{l}\text { Total aromatics } \\
(\% \mathrm{~m} / \mathrm{m})\end{array}$ & 0.0 & 23.5 & 0.0 & 0.0 & 0.0 & 0.2 & 0.2 \\
\hline Cloud Point $\left({ }^{\circ} \mathbf{C}\right)$ & -45 & -43 & -1 & -1 & -35 & -19 & -7 \\
\hline
\end{tabular}


Table 3

Combustion Characteristics of NDH with Ignition Improver Start of Injection (CSOI) and Constant Start of Combustion (CSOC) Tests.

\begin{tabular}{|c|c|c|c|c|c|c|c|c|c|c|c|c|}
\hline Test Type & $\begin{array}{l}\text { Fuel } \\
\text { Type }\end{array}$ & $\begin{array}{l}\text { IMEP } \\
\text { [Bar] }\end{array}$ & $\begin{array}{l}\text { 2-EHN } \\
\text { Conc. } \\
\text { [vol.\%] }\end{array}$ & $\begin{array}{l}\text { Ignition } \\
\text { Delay } \\
{\left[{ }^{\circ} \mathbf{C A}\right]}\end{array}$ & $\begin{array}{l}\text { Start of } \\
\text { Injection } \\
\text { Timing } \\
{\left[{ }^{\circ} \mathrm{CA}\right]}\end{array}$ & $\begin{array}{l}\text { Start of } \\
\text { Combustion } \\
\text { Timing } \\
{\left[{ }^{\circ} \mathbf{C A}\right]}\end{array}$ & $\begin{array}{l}\text { Max. Heat } \\
\text { Release } \\
\text { Rate } \\
{[\text { J/deg] }}\end{array}$ & $\begin{array}{l}\text { Max. Heat } \\
\text { Release } \\
\text { Rate } \\
\text { Timing } \\
{\left[{ }^{\circ} \mathrm{CA}\right]}\end{array}$ & $\begin{array}{l}\text { Max. In- } \\
\text { Cylinder } \\
\text { Temperature } \\
{[\mathrm{K}]}\end{array}$ & $\begin{array}{l}\text { Max. In- } \\
\text { Cylinder } \\
\text { Temperature } \\
\text { Timing } \\
{\left[{ }^{\circ} \mathrm{CA}\right]}\end{array}$ & $\begin{array}{l}\text { Premixed } \\
\text { Burn } \\
{[\%]}\end{array}$ & $\begin{array}{l}\text { Combustion } \\
\text { Duration } \\
{\left[{ }^{\circ} \mathrm{CA}\right]}\end{array}$ \\
\hline \multirow[t]{7}{*}{ CSOI } & NDH & 4 & 0 & 6 & 357 & 363 & 145.7 & 366.2 & 1220.6 & 375.8 & 57.3 & 31.6 \\
\hline & NDH & 4 & 0.18 & 5.4 & 357 & 362.4 & 112.4 & 365.4 & 1226.7 & 377 & 51.9 & 33.2 \\
\hline & NDH & 4 & 0.27 & 5.2 & 357 & 362.2 & 105.8 & 365 & 1224 & 376.8 & 44.7 & 37 \\
\hline & NDH & 4 & 0.55 & 4.8 & 357 & 361.8 & 94.2 & 364.6 & 1223.7 & 376.6 & 41.3 & 37.4 \\
\hline & NDH & 4 & 1.05 & 4.8 & 357 & 361.8 & 83.4 & 364.4 & 1211.2 & 376.4 & 34.6 & 37.2 \\
\hline & NDH & 4 & 2.11 & 4.4 & 357 & 361.4 & 71.1 & 363.8 & 1200.2 & 376.2 & 26.1 & 37.6 \\
\hline & NDH & 4 & 2.89 & 4.2 & 357 & 361.2 & 63 & 363.6 & 1209.5 & 376.2 & 21.9 & 36.8 \\
\hline \multirow[t]{7}{*}{ CSOI } & NDH & 6 & 0 & 5.7 & 354.5 & 360.2 & 116.6 & 362.8 & 1448.2 & 379.4 & 33.7 & 44.6 \\
\hline & NDH & 6 & 0.18 & 5.1 & 354.5 & 359.6 & 90.5 & 362 & 1458.4 & 379.4 & 24.6 & 44.6 \\
\hline & NDH & 6 & 0.27 & 5.1 & 354.5 & 359.6 & 86.9 & 361.8 & 1456 & 379.8 & 24.2 & 44.4 \\
\hline & NDH & 6 & 0.55 & 4.9 & 354.5 & 359.4 & 79.9 & 361.6 & 1455.5 & 380 & 23 & 44 \\
\hline & NDH & 6 & 1.05 & 4.7 & 354.5 & 359.2 & 71.6 & 361.2 & 1441.9 & 380 & 16.8 & 44 \\
\hline & NDH & 6 & 2.11 & 4.5 & 354.5 & 359 & 61.7 & 361 & 1433.2 & 379.8 & 13.8 & 44.2 \\
\hline & NDH & 6 & 2.89 & 4.3 & 354.5 & 358.8 & 54.8 & 360.6 & 1440.4 & 379.8 & 12.5 & 44.8 \\
\hline \multirow[t]{7}{*}{ CSOC } & NDH & 4 & 0 & 6 & 354 & 360 & 136.5 & 363 & 1232.6 & 375 & 54.5 & 30.6 \\
\hline & NDH & 4 & 0.2 & 5.6 & 354.4 & 360 & 103.6 & 362.8 & 1238.6 & 374.8 & 42 & 39.6 \\
\hline & NDH & 4 & 0.27 & 5 & 355 & 360 & 99.2 & 362.6 & 1235.6 & 374.6 & 40.4 & 39.6 \\
\hline & NDH & 4 & 0.56 & 5 & 355 & 360 & 88.6 & 362.4 & 1233.9 & 374.6 & 36.7 & 37 \\
\hline & NDH & 4 & 1.06 & 5 & 355 & 360 & 80 & 362.6 & 1217.5 & 374.8 & 31.8 & 37.2 \\
\hline & NDH & 4 & 2.07 & 4.4 & 355.6 & 360 & 68.9 & 362.2 & 1208.5 & 376 & 25.2 & 37.2 \\
\hline & NDH & 4 & 2.87 & 4.2 & 355.8 & 360 & 61 & 362 & 1230.3 & 376 & 20.8 & 37.2 \\
\hline \multirow[t]{7}{*}{ CSOC } & NDH & 6 & 0 & 5.6 & 354.4 & 360 & 116.7 & 362.8 & 1451.6 & 379.4 & 32.7 & 41 \\
\hline & NDH & 6 & 0.2 & 5.2 & 354.8 & 360 & 90.6 & 362.4 & 1456 & 379.8 & 24.3 & 44.6 \\
\hline & NDH & 6 & 0.27 & 5 & 355 & 360 & 85.9 & 362.4 & 1453.9 & 380 & 23.4 & 44.2 \\
\hline & NDH & 6 & 0.56 & 4.8 & 355.2 & 360 & 79.4 & 362.4 & 1448.8 & 380.6 & 21.2 & 44.4 \\
\hline & NDH & 6 & 1.06 & 4.6 & 355.4 & 360 & 72 & 362.2 & 1434.7 & 381 & 17.2 & 45.6 \\
\hline & NDH & 6 & 2.07 & 4.2 & 355.8 & 360 & 63.3 & 362 & 1428.4 & 380.8 & 15.4 & 46 \\
\hline & NDH & 6 & 2.87 & 4.2 & 355.8 & 360 & 56.9 & 362 & 1431 & 381.2 & 13.5 & 47.4 \\
\hline
\end{tabular}


Table 4

Combustion Characteristics of Different Fuel Molecules Start of Injection (CSOI) and Constant Start of Combustion (CSOC) Tests.

\begin{tabular}{|c|c|c|c|c|c|c|c|c|c|c|c|}
\hline Test Type & Fuel Type & IMEP [Bar] & $\begin{array}{l}\text { Ignition Delay } \\
{\left[{ }^{\circ} \mathrm{CA}\right]}\end{array}$ & $\begin{array}{l}\text { Start } \\
\text { Injection } \\
\text { Timing } \\
{\left[{ }^{\circ} \mathrm{CA}\right]}\end{array}$ & $\begin{array}{l}\text { Start of } \\
\text { Combustion } \\
\text { Timing } \\
{\left[{ }^{\circ} \mathrm{CA}\right]}\end{array}$ & $\begin{array}{l}\text { Max. Heat } \\
\text { Release Rate } \\
\text { [J/deg] }\end{array}$ & $\begin{array}{ll}\text { Max. } & \text { Heat } \\
\text { Release } & \text { Rate } \\
\text { Timing } & \\
{\left[{ }^{\circ} \mathrm{CA}\right]} & \end{array}$ & $\begin{array}{l}\text { Max. In- } \\
\text { Cylinder } \\
\text { Temperature } \\
{[\mathrm{K}]}\end{array}$ & $\begin{array}{l}\text { Max. In- } \\
\text { Cylinder } \\
\text { Temperature } \\
\text { Timing } \\
{\left[{ }^{\circ} \mathrm{CA}\right]}\end{array}$ & $\begin{array}{l}\text { Premixed } \\
\text { Burn } \\
{[\%]}\end{array}$ & $\begin{array}{l}\text { Combustion } \\
\text { Duration } \\
{\left[{ }^{\circ} \mathrm{CA}\right]}\end{array}$ \\
\hline \multirow[t]{7}{*}{$\overline{\mathrm{CSOI}}$} & DH & 4 & 6.4 & 357 & 363.4 & 157.3 & 366.6 & 1226.7 & 375.8 & 62.4 & 31.2 \\
\hline & NDH & 4 & 6 & 357 & 363 & 145.7 & 366.2 & 1220.6 & 375.8 & 57.3 & 31.6 \\
\hline & SME & 4 & 5.4 & 357 & 362.4 & 99.8 & 365.2 & 1217.1 & 377 & 48.9 & 36.6 \\
\hline & RME & 4 & 4.8 & 357 & 361.8 & 80.1 & 364.3 & 1216 & 376.4 & 32.9 & 36 \\
\hline & HP & 4 & 4.8 & 357 & 361.8 & 74.5 & 364 & 1199.1 & 376.6 & 29.6 & 38.4 \\
\hline & $10 \mathrm{P}$ & 4 & 4.6 & 357 & 361.6 & 71 & 363.6 & 1209.8 & 375.8 & 24.4 & 36 \\
\hline & $\mathbf{P}$ & 4 & 4.6 & 357 & 361.6 & 70 & 363.6 & 1208.1 & 376.8 & 24.3 & 36 \\
\hline \multirow[t]{7}{*}{ CSOI } & DH & 6 & 5.9 & 354.5 & 360.4 & 125.15 & 363 & 1463 & 378.2 & 33.7 & 35.2 \\
\hline & NDH & 6 & 5.7 & 354.5 & 360.2 & 116.6 & 362.8 & 1448.2 & 379.4 & 33.8 & 44.6 \\
\hline & SME & 6 & 5.1 & 354.5 & 359.6 & 82.8 & 361.8 & 1468.9 & 378.6 & 23.2 & 42.6 \\
\hline & RME & 6 & 4.9 & 354.5 & 359.4 & 69.8 & 361.2 & 1464 & 379.3 & 19.6 & 42.6 \\
\hline & HP & 6 & 4.7 & 354.5 & 359.2 & 63.2 & 361 & 1437.1 & 380 & 15.2 & 46.8 \\
\hline & $10 \mathrm{P}$ & 6 & 4.5 & 354.5 & 359 & 60.9 & 360.6 & 1456.5 & 379.2 & 13.6 & 43 \\
\hline & $\mathbf{P}$ & 6 & 4.5 & 354.5 & 359 & 59 & 360.8 & 1449 & 379.6 & 13.9 & 45.4 \\
\hline \multirow[t]{7}{*}{ CSOC } & DH & 4 & 6.4 & 353.6 & 360 & 149.3 & 363 & 1242.1 & 375 & 57.8 & 31.2 \\
\hline & NDH & 4 & 6 & 354 & 360 & 136.5 & 363 & 1232.6 & 375 & 54.5 & 30.6 \\
\hline & SME & 4 & 5.4 & 354.6 & 360 & 93.2 & 362.4 & 1240.9 & 374.6 & 38.8 & 36.2 \\
\hline & RME & 4 & 4.8 & 355.2 & 360 & 77.9 & 362.2 & 1239.8 & 375.4 & 31.6 & 35.8 \\
\hline & HP & 4 & 4.8 & 355.2 & 360 & 69.6 & 362.2 & 1212.3 & 375.8 & 25.8 & 39.8 \\
\hline & $10 P$ & 4 & 4.6 & 355.4 & 360 & 67.5 & 362 & 1232.3 & 375.8 & 22.1 & 36.4 \\
\hline & $\mathbf{P}$ & 4 & 4.6 & 355.4 & 360 & 66.8 & 361.8 & 1225.3 & 375.8 & 22.7 & 36.4 \\
\hline \multirow[t]{7}{*}{ CSOC } & DH & 6 & 6 & 354 & 360 & 126.7 & 362.8 & 1461.3 & 379.2 & 33.4 & 36 \\
\hline & NDH & 6 & 5.6 & 354.4 & 360 & 116.7 & 362.8 & 1451.6 & 379.4 & 32.7 & 41 \\
\hline & SME & 6 & 5 & 355 & 360 & 83.3 & 362.2 & 1467.5 & 379 & 23 & 43 \\
\hline & RME & 6 & 4.8 & 355.2 & 360 & 69.7 & 362 & 1466.3 & 379.4 & 18.2 & 42.8 \\
\hline & HP & 6 & 4.6 & 355.4 & 360 & 63.2 & 362 & 1427.2 & 381.2 & 15.4 & 49 \\
\hline & $10 \mathrm{P}$ & 6 & 4.4 & 355.6 & 360 & 61.1 & 361.8 & 1446 & 380.4 & 13.3 & 45.2 \\
\hline & $\mathbf{P}$ & 6 & 4.4 & 355.6 & 360 & 60.2 & 361.8 & 1445.5 & 380.4 & 14.4 & 43.4 \\
\hline
\end{tabular}




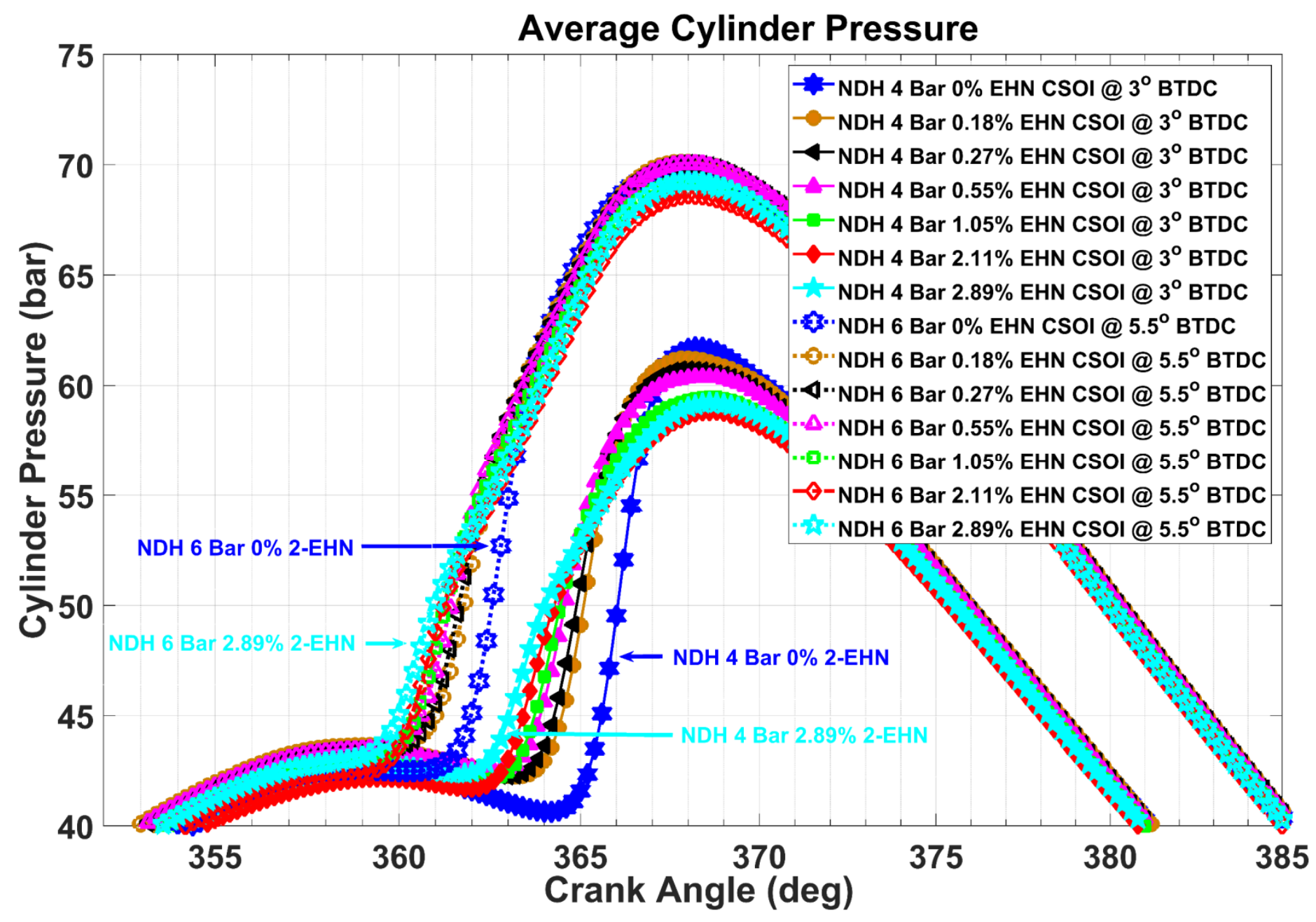

Fig. 1. In-cylinder pressure profiles for constant start of injection (CSOI) tests at 4 bar and 6 bar IMEP for the experimental set of NDH with ignition improver. 


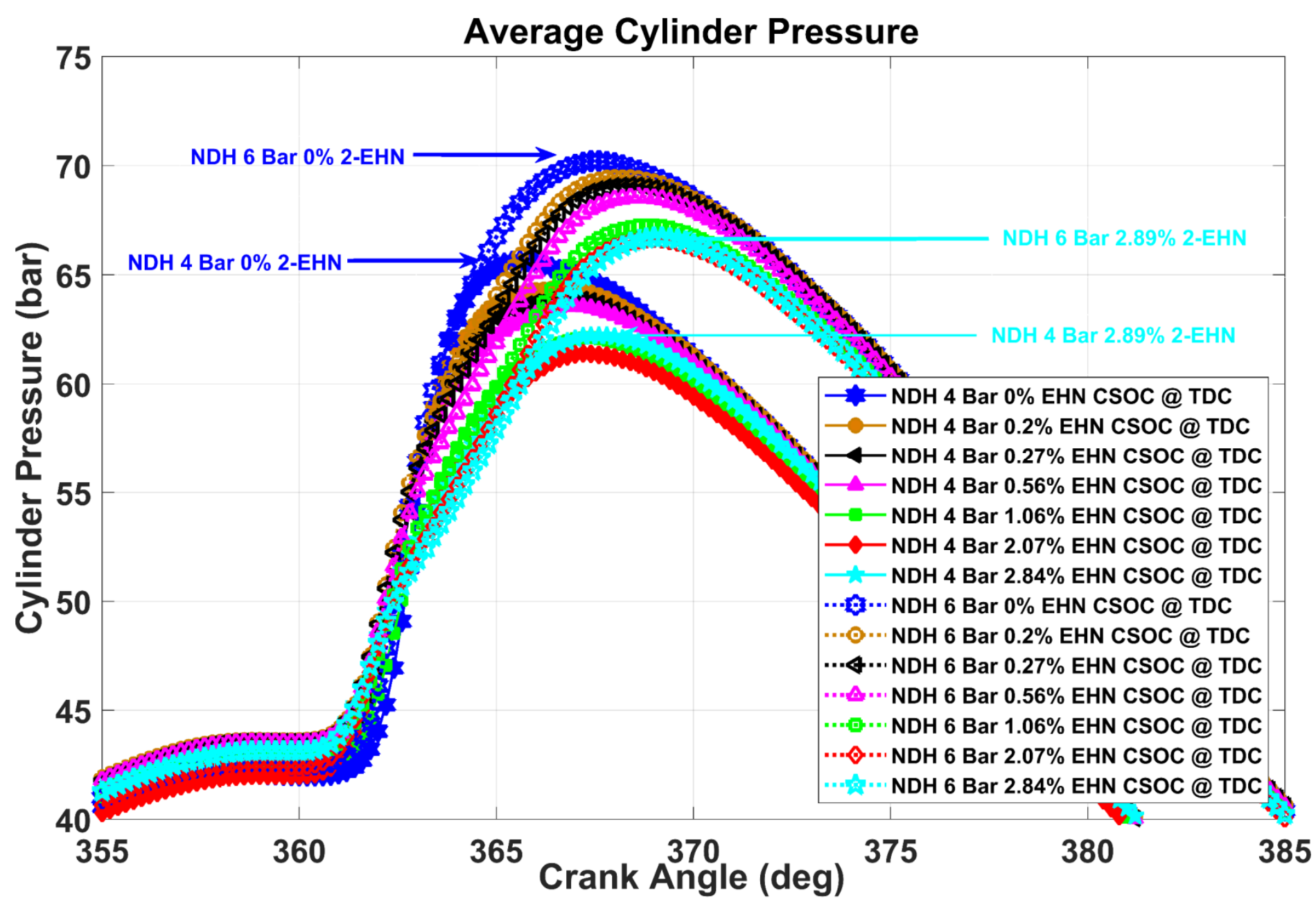

Fig. 2. In-cylinder pressure profiles for constant start of combustion (CSOC) at top dead center (TDC) tests at 4 bar and 6 bar IMEP for the experimental set of NDH with ignition improver. 


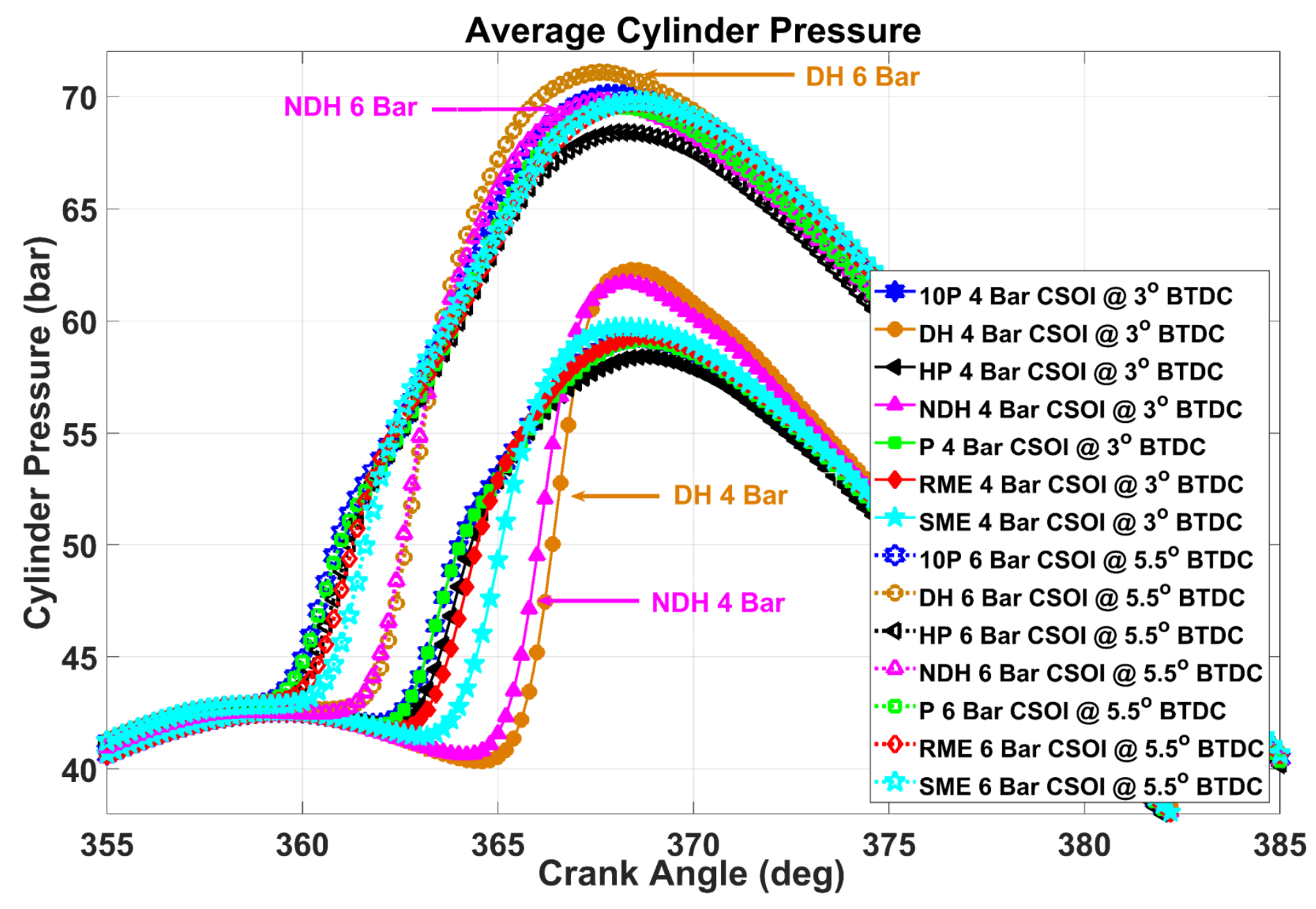

Fig. 3. In-cylinder pressure profiles for constant start of injection (CSOI) tests at 4 bar and 6 bar IMEP for the experimental set of fuels with different CN. 


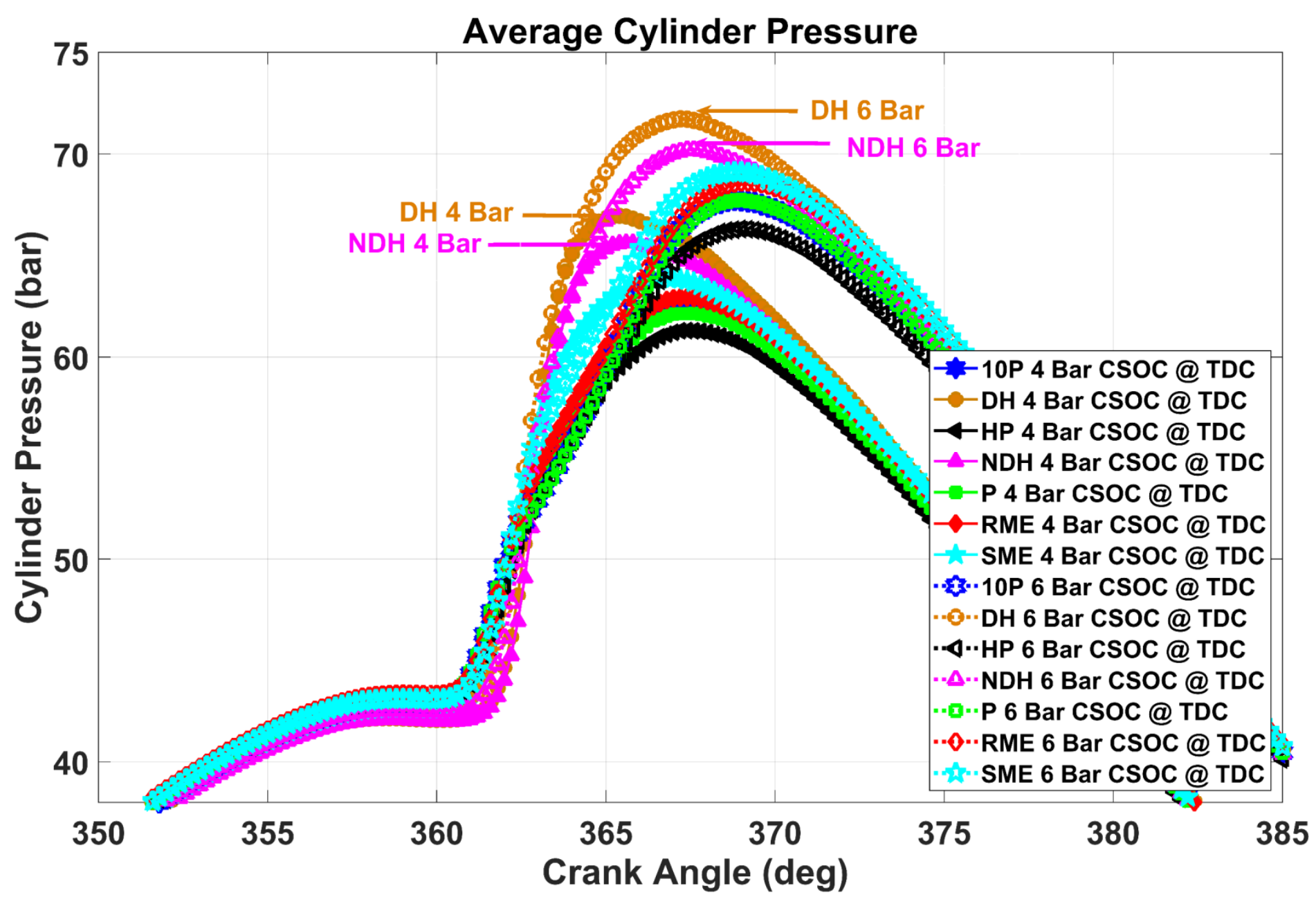

Fig. 4. In-cylinder pressure profiles for constant start of combustion (CSOC) at top dead center (TDC) tests at 4 bar and 6 bar IMEP for the experimental set of different fuel molecules. 


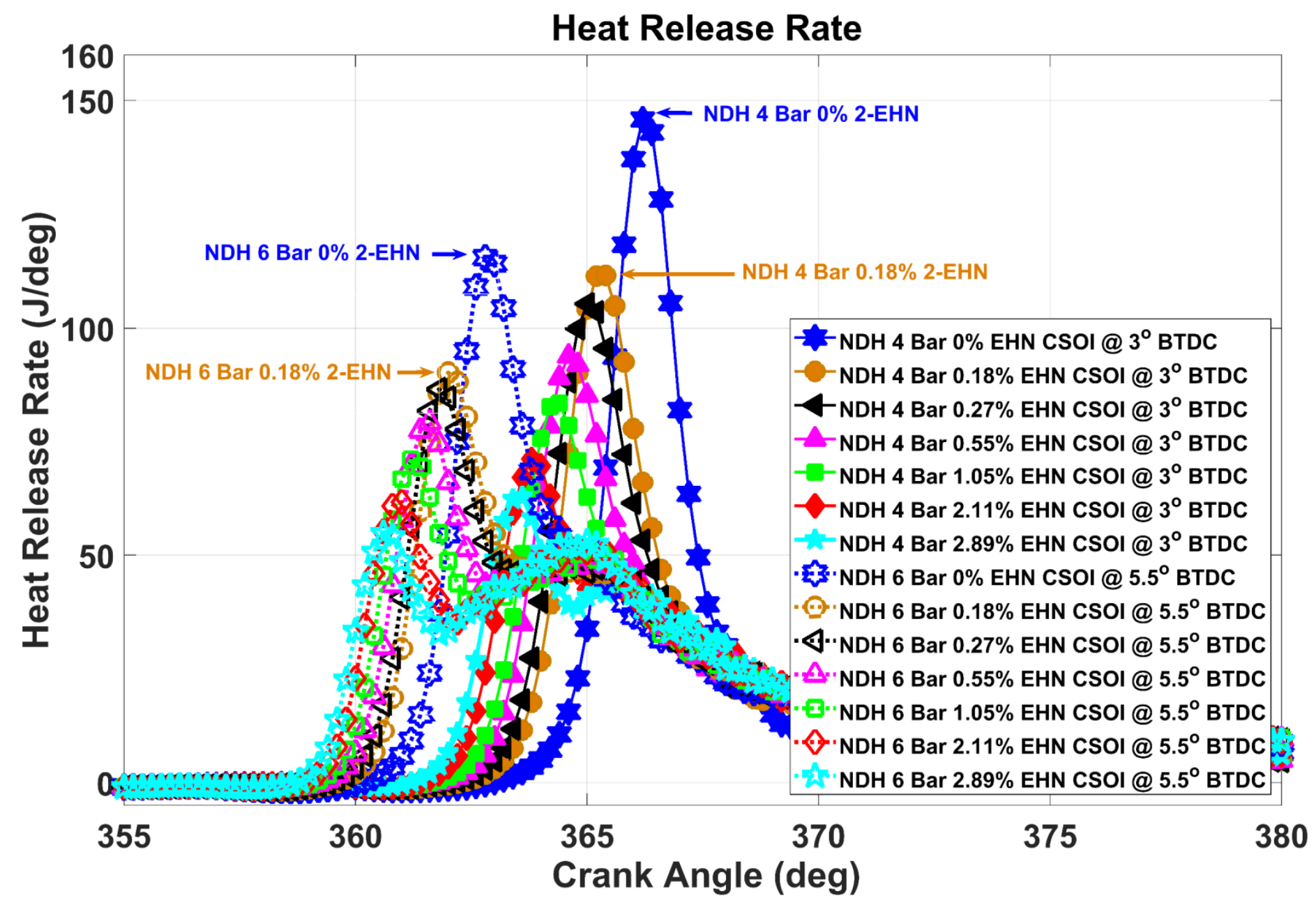

Fig. 5. Heat release rate profiles for constant start of injection (CSOI) tests at 4 bar and 6 bar IMEP for the experimental set of NDH with ignition improver. 


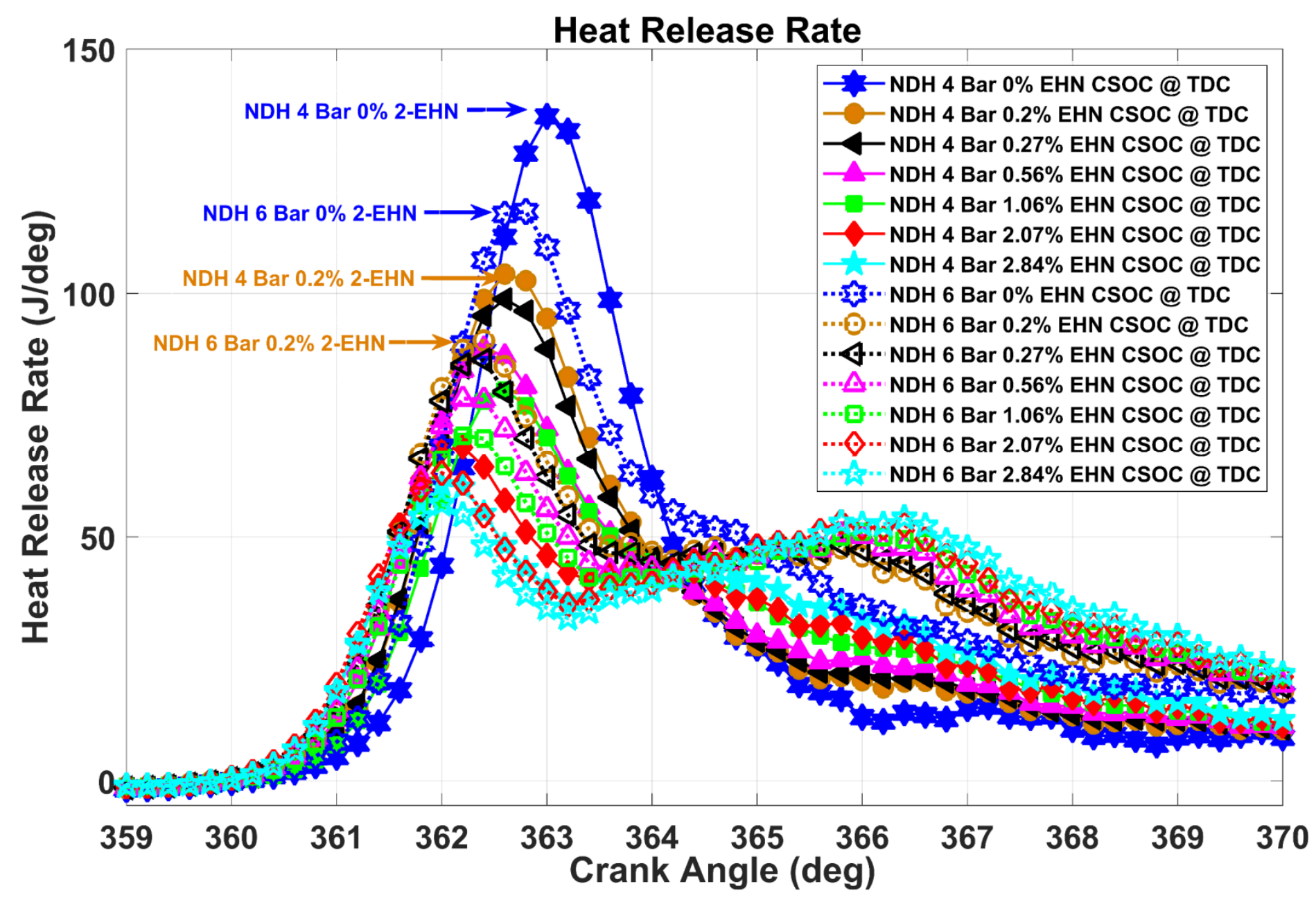

Fig. 6. Heat release rate profiles for constant start of combustion (CSOC) at top dead center (TDC) tests at 4 bar and 6 bar IMEP for the experimental set of NDH with ignition improver. 


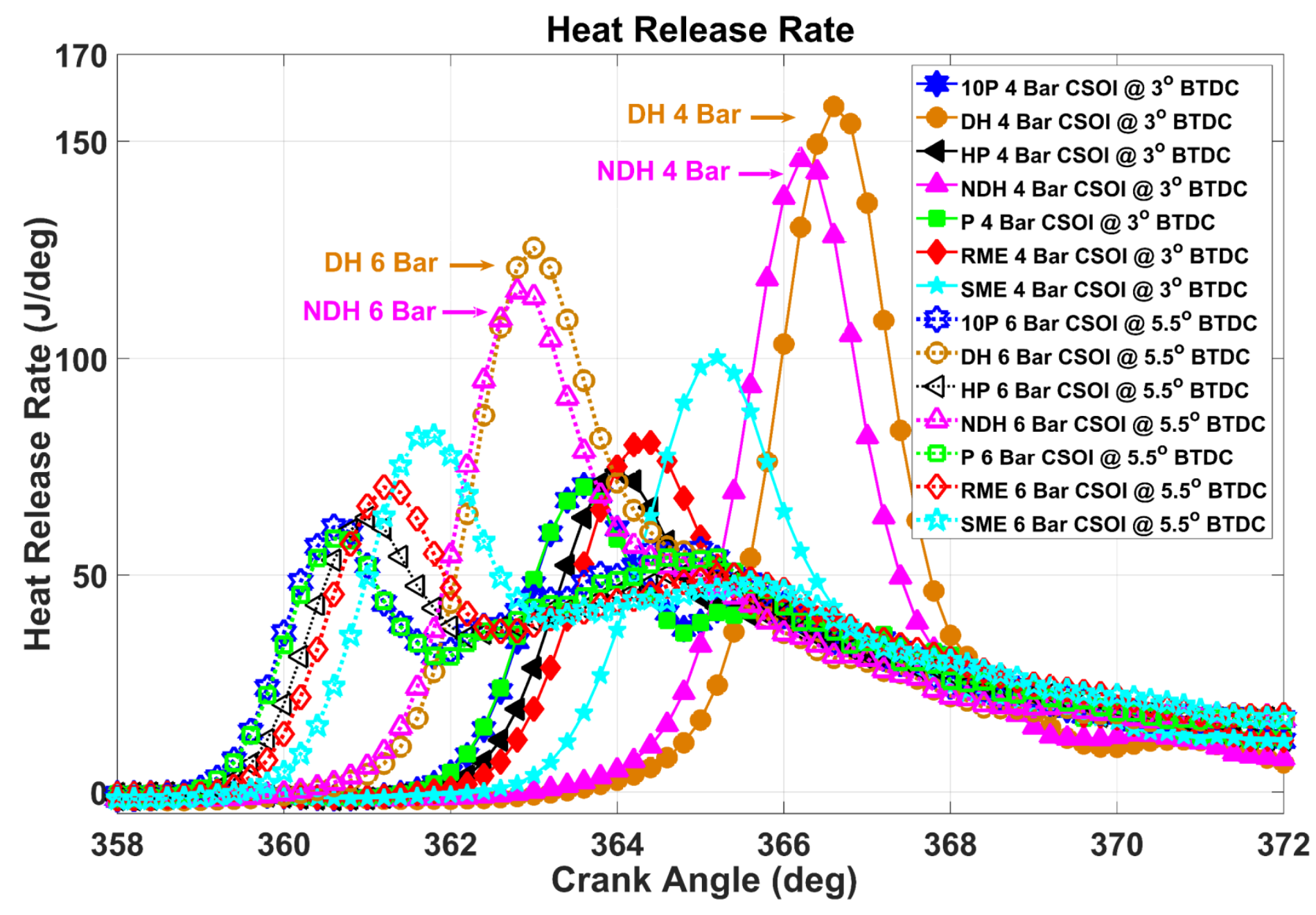

Fig. 7. Heat release rate profiles for constant start of injection (CSOI) tests at 4 bar and 6 bar IMEP for the experimental set of fuels with different CN. 


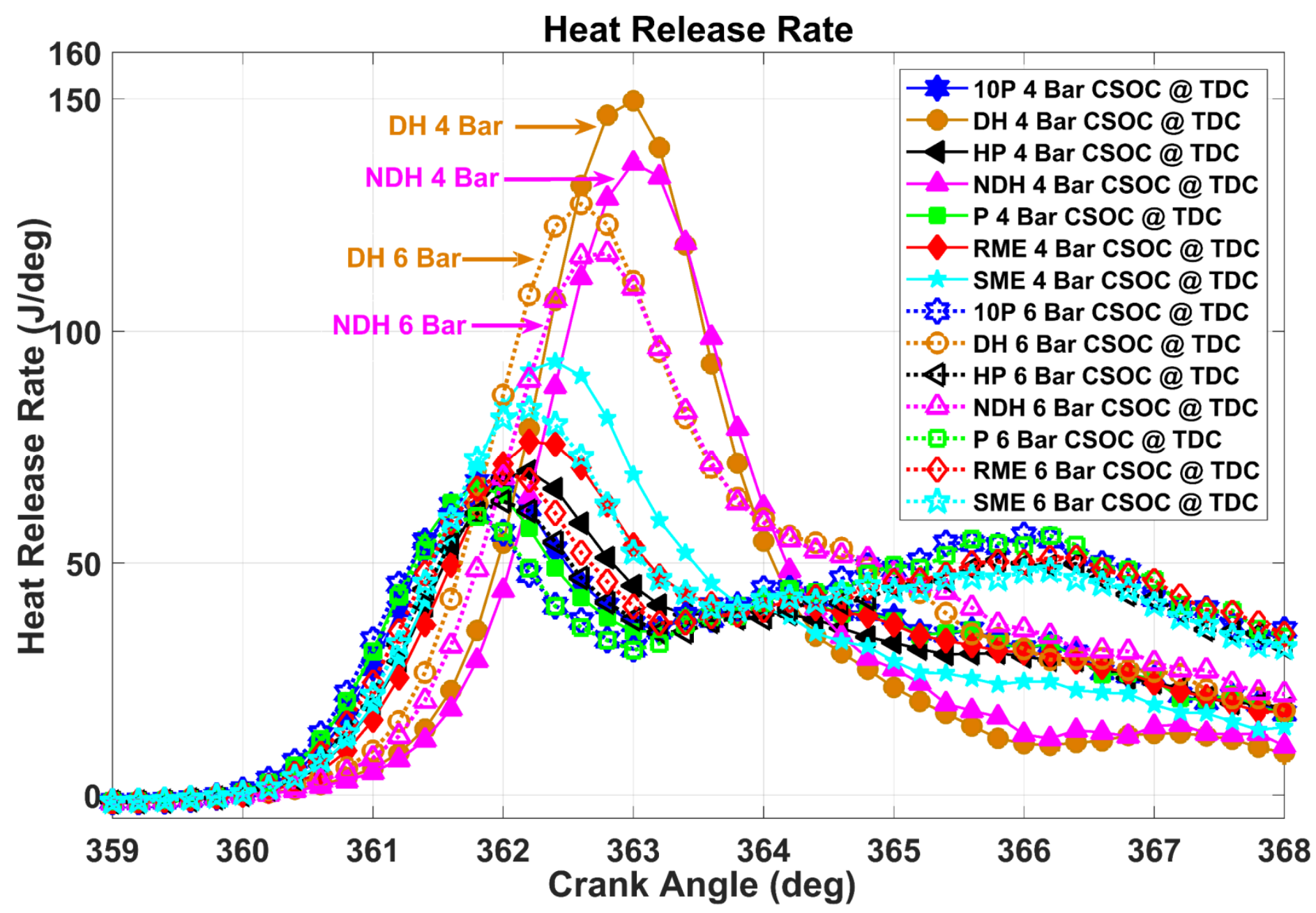

Fig. 8. Heat release rate profiles for constant start of combustion (CSOC) at top dead center (TDC) tests at 4 bar and 6 bar IMEP for the experimental set of fuels with different CN. 


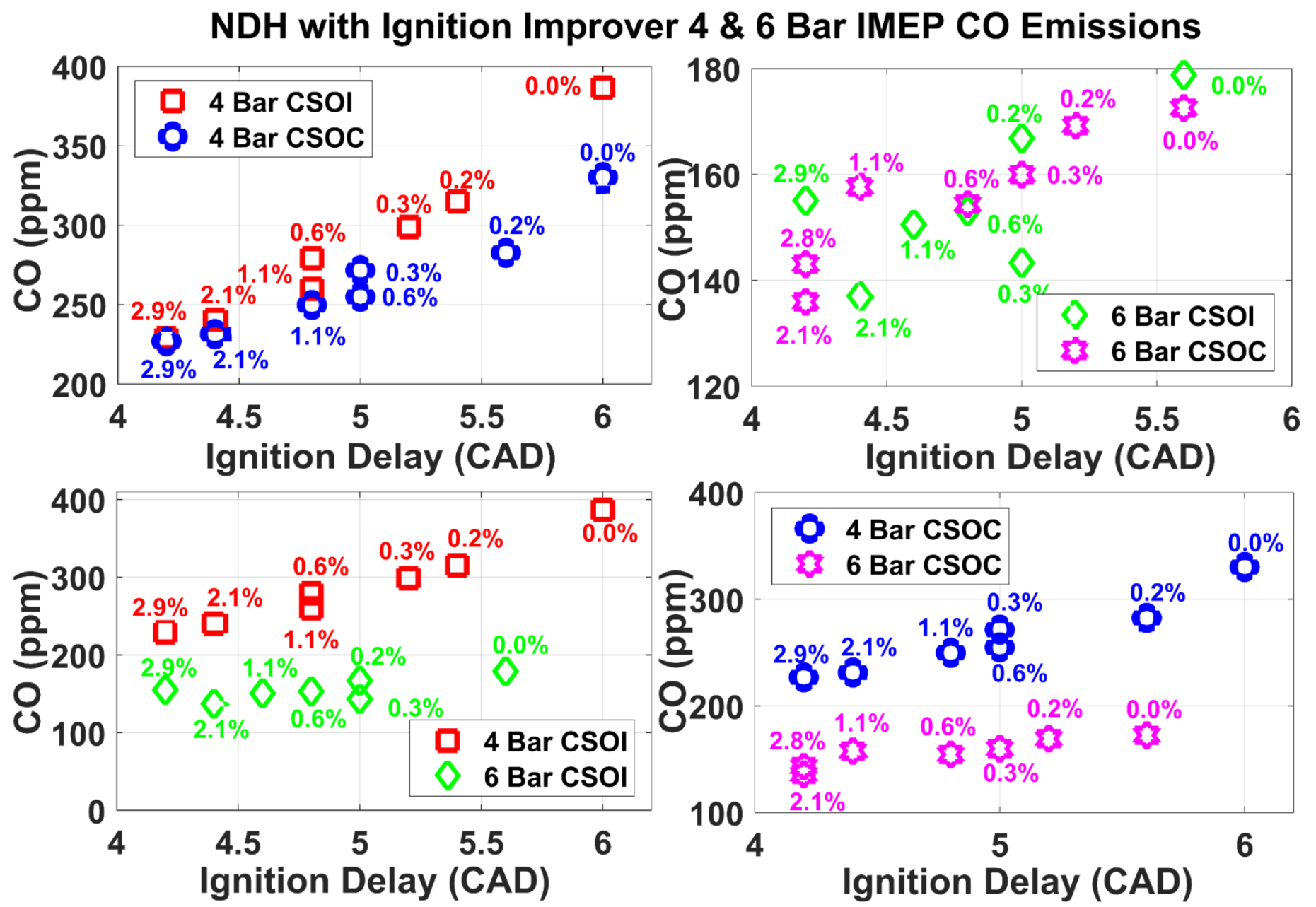

Fig. 9. Ignition delay effect on $\mathrm{CO}$ concentrations for experimental set of NDH with ignition improver at both timing conditions at 4 bar and 6 bar IMEP. 


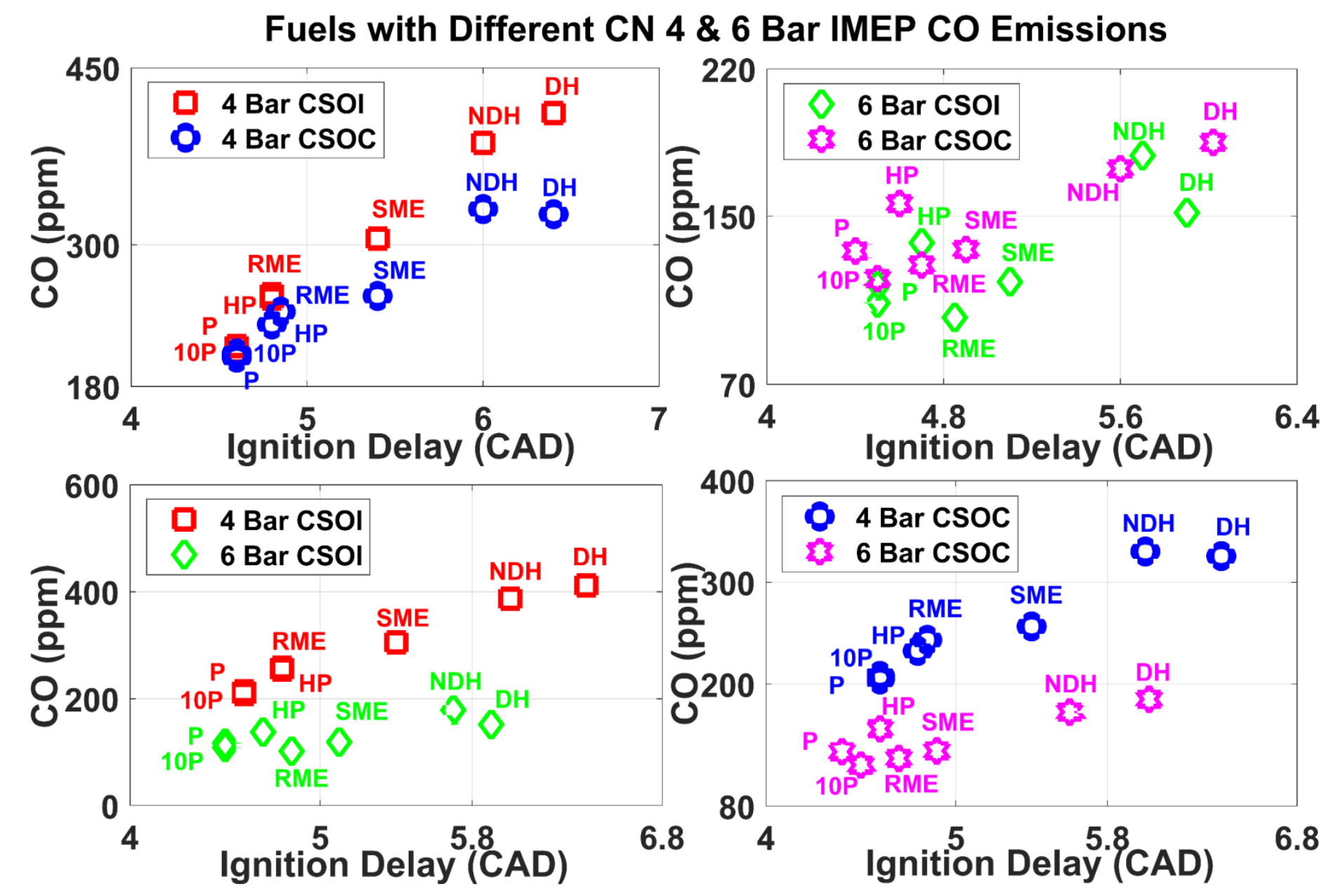

Fig. 10. Ignition delay effect on $\mathrm{CO}$ concentrations for experimental set of fuels with different $\mathrm{CN}$ at both timing conditions at 4 bar and 6 bar IMEP. 


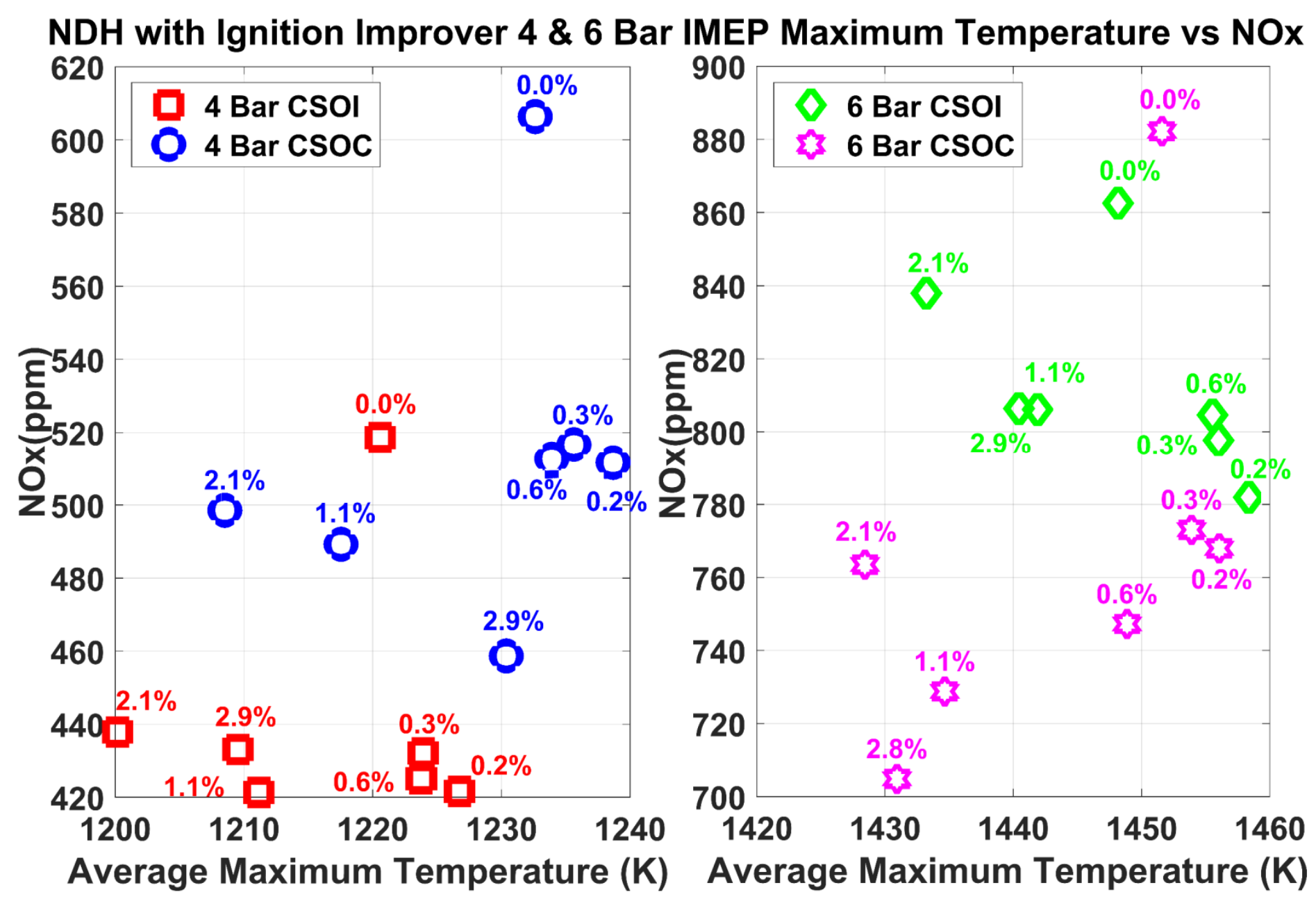

Fig. 11. Effect of maximum global in-cylinder temperature on $\mathrm{NO}_{\mathrm{x}}$ emissions at constant injection (CSOI) and constant combustion (CSOC) timing at 4 bar and 6 bar IMEP for experimental set of NDH with ignition improver. 
Fuels with Different CN 4 \& 6 Bar IMEP Maximum Temperature and NOx

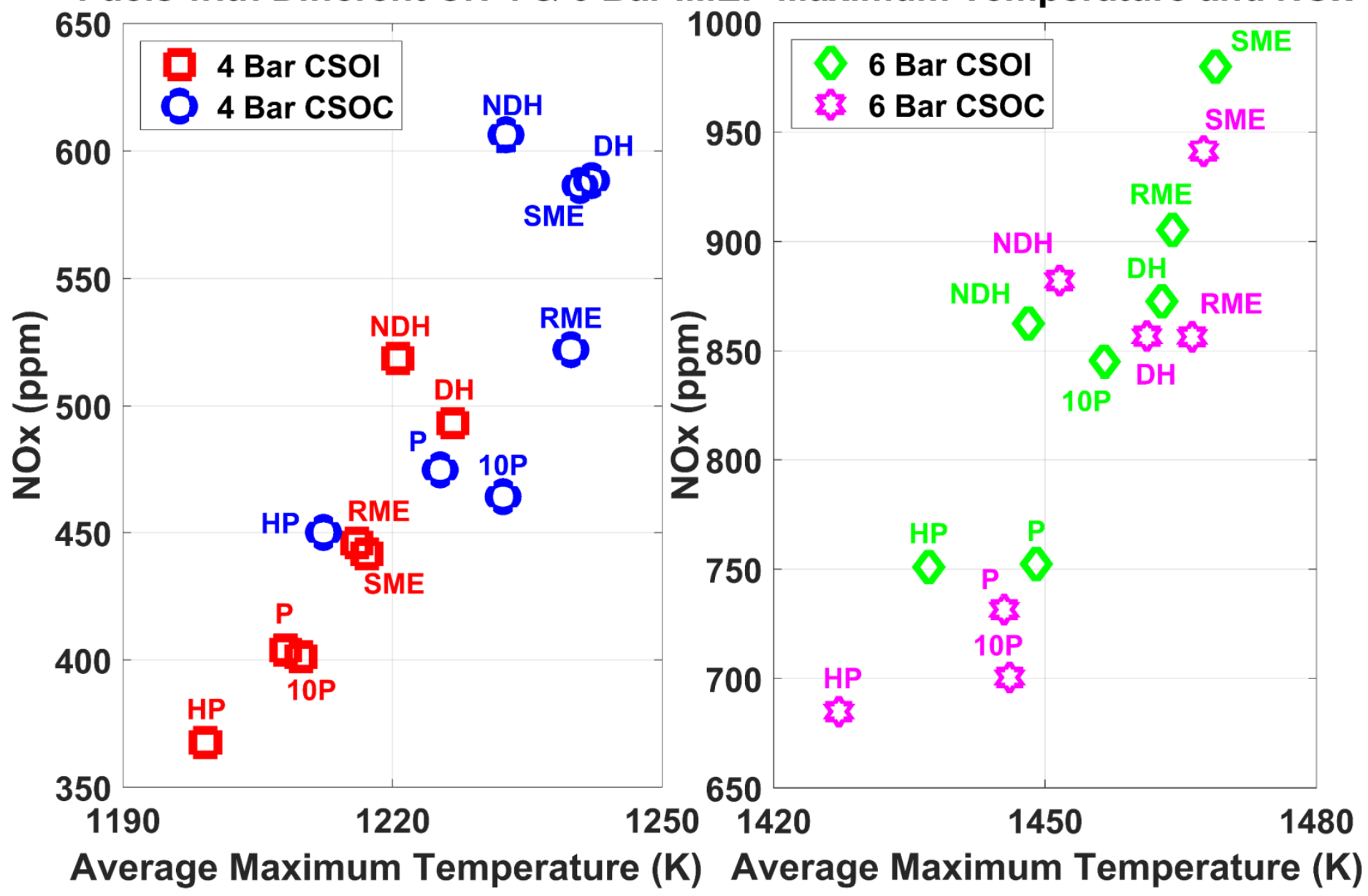

Fig. 12. Effect of maximum global in-cylinder temperature on $\mathrm{NO}_{\mathrm{x}}$ emissions at constant injection (CSOI) and constant combustion (CSOC) timing at 4 bar and 6 bar IMEP for experimental set of fuels with different $\mathrm{CN}$. 


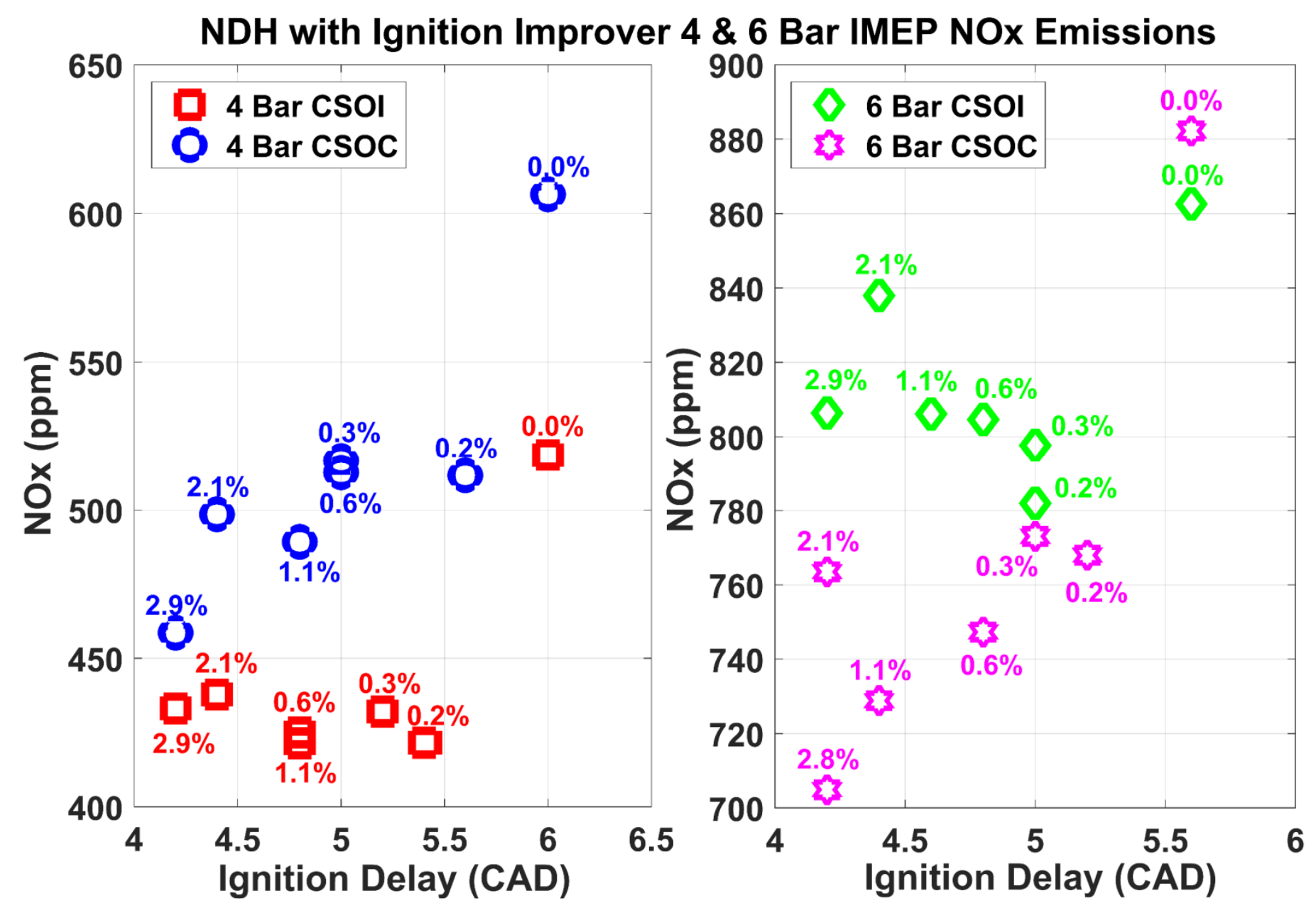

Fig. 13. Ignition delay effect on $\mathrm{NO}_{\mathrm{x}}$ emissions for experimental set of $\mathrm{NDH}$ with ignition improver at both timing conditions at 4 bar and 6 bar IMEP. 


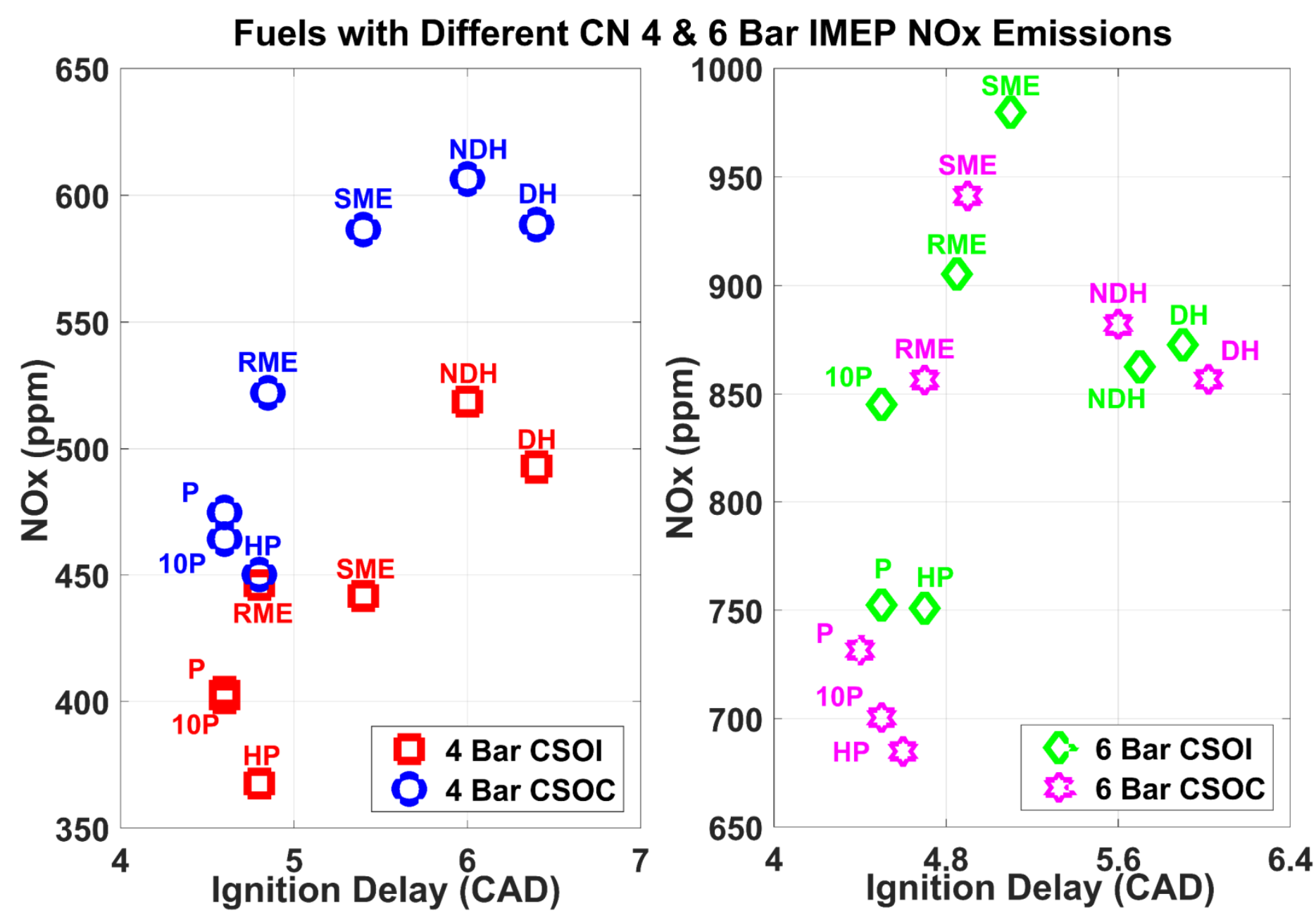

Fig. 14. Ignition delay effect on NOx emissions for experimental set of fuels with different $\mathrm{CN}$ at both timing conditions at 4 bar and 6 bar IMEP. 


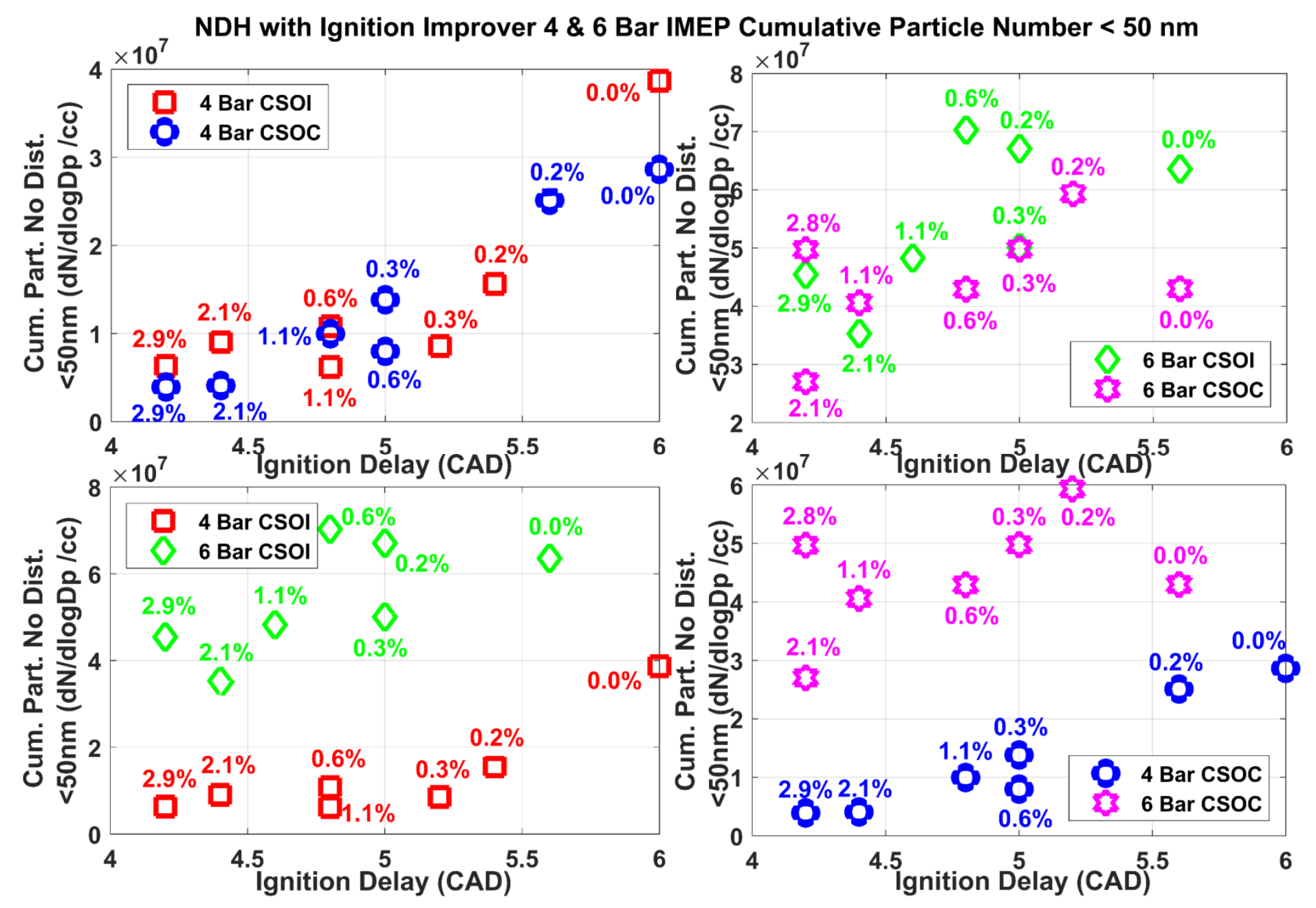

Fig. 15. Effect of ignition delay on particle number in nucleation mode at constant injection (CSOI) and constant combustion (CSOC) timing at 4 bar and 6 bar IMEP for the experimental set of $\mathrm{NDH}$ with ignition improver 

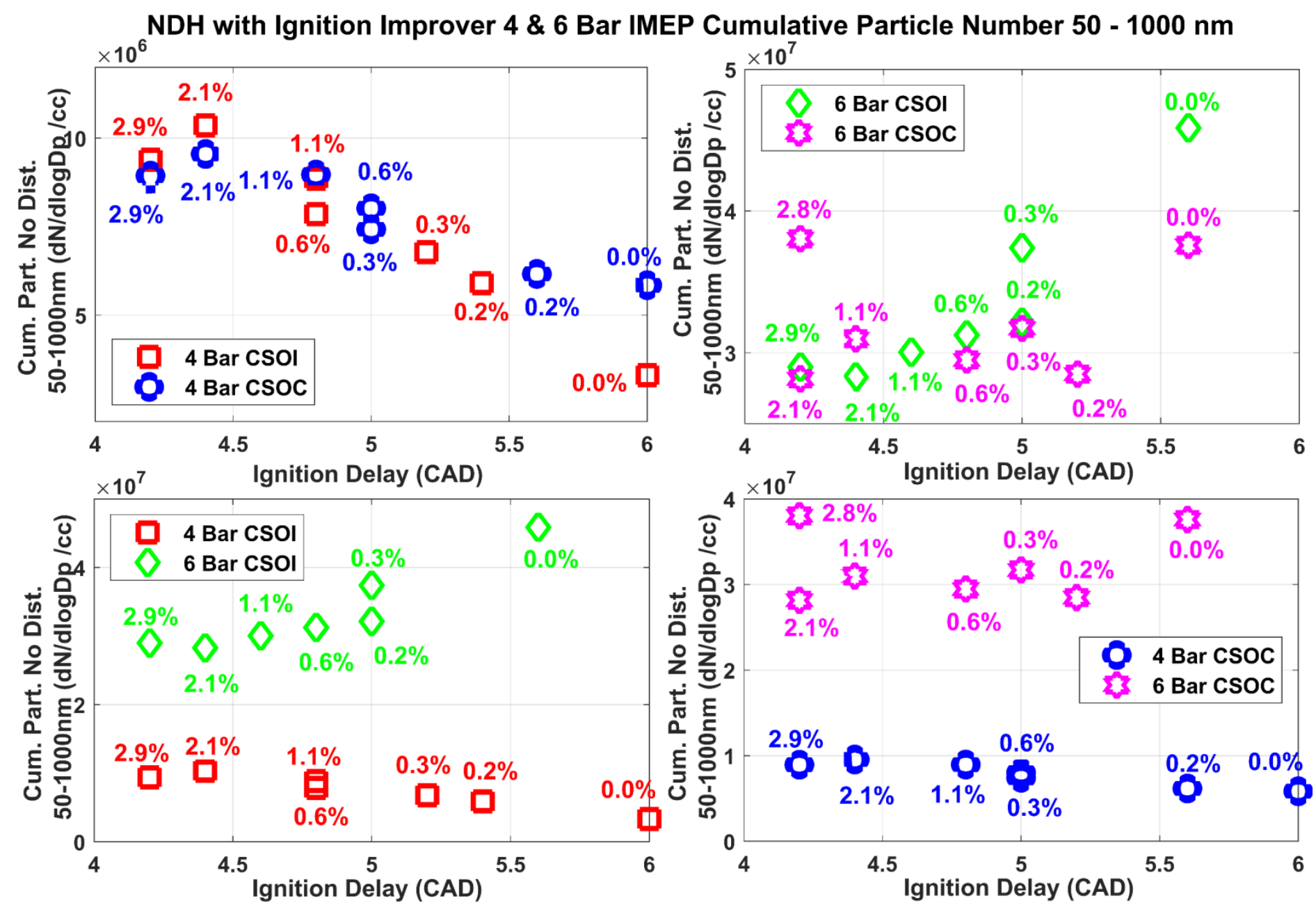

Fig. 16. Effect of ignition delay on particle number in accumulation mode at constant injection (CSOI) and constant combustion (CSOC) timing at 4 bar and 6 bar IMEP for the experimental set of NDH with ignition improver. 


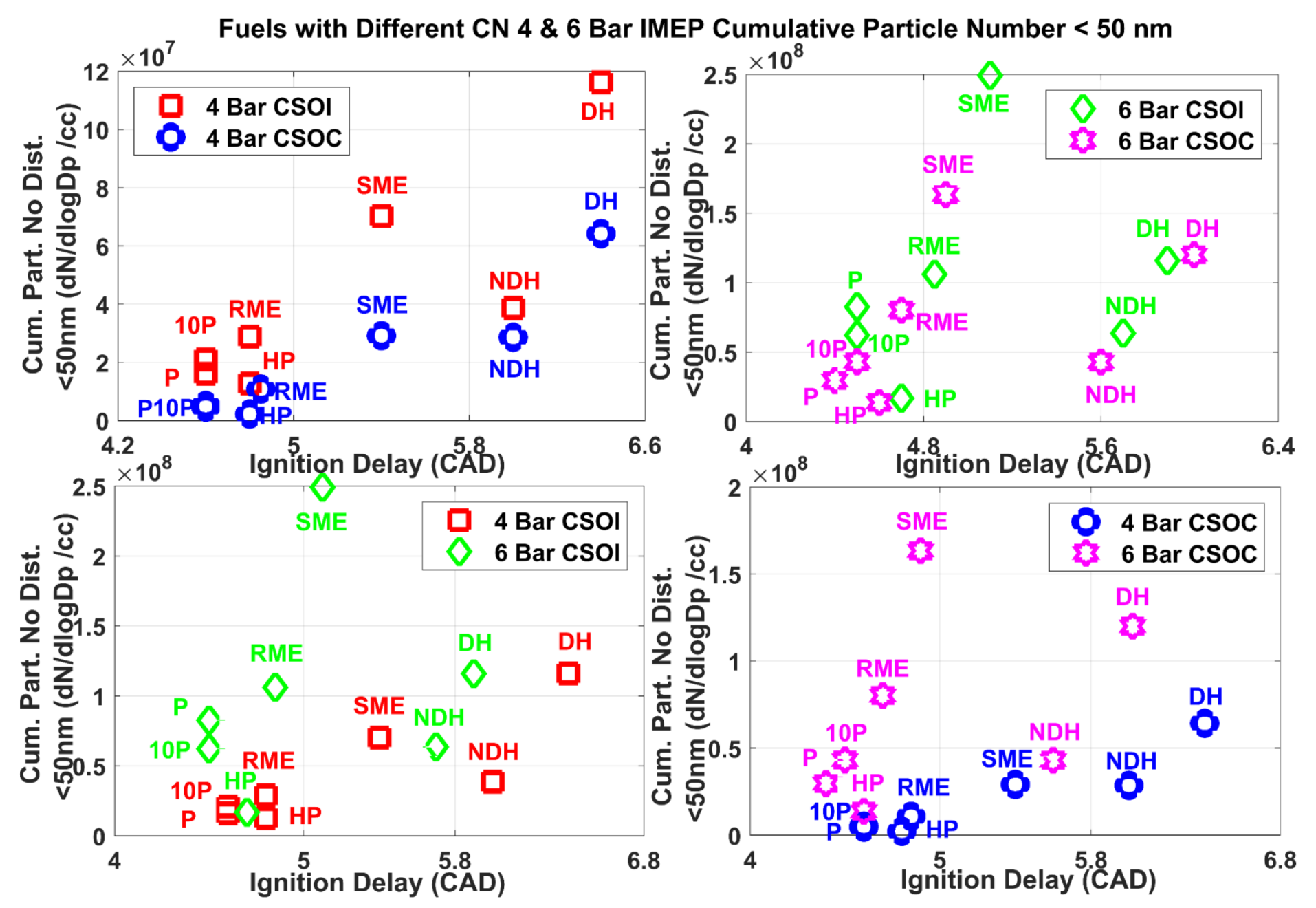

Fig. 17. Effect of ignition delay on particle number in nucleation mode at constant injection (CSOI) and constant combustion (CSOC) timing at 4 bar and 6 bar IMEP for the experimental set of fuels with different $\mathrm{CN}$. 

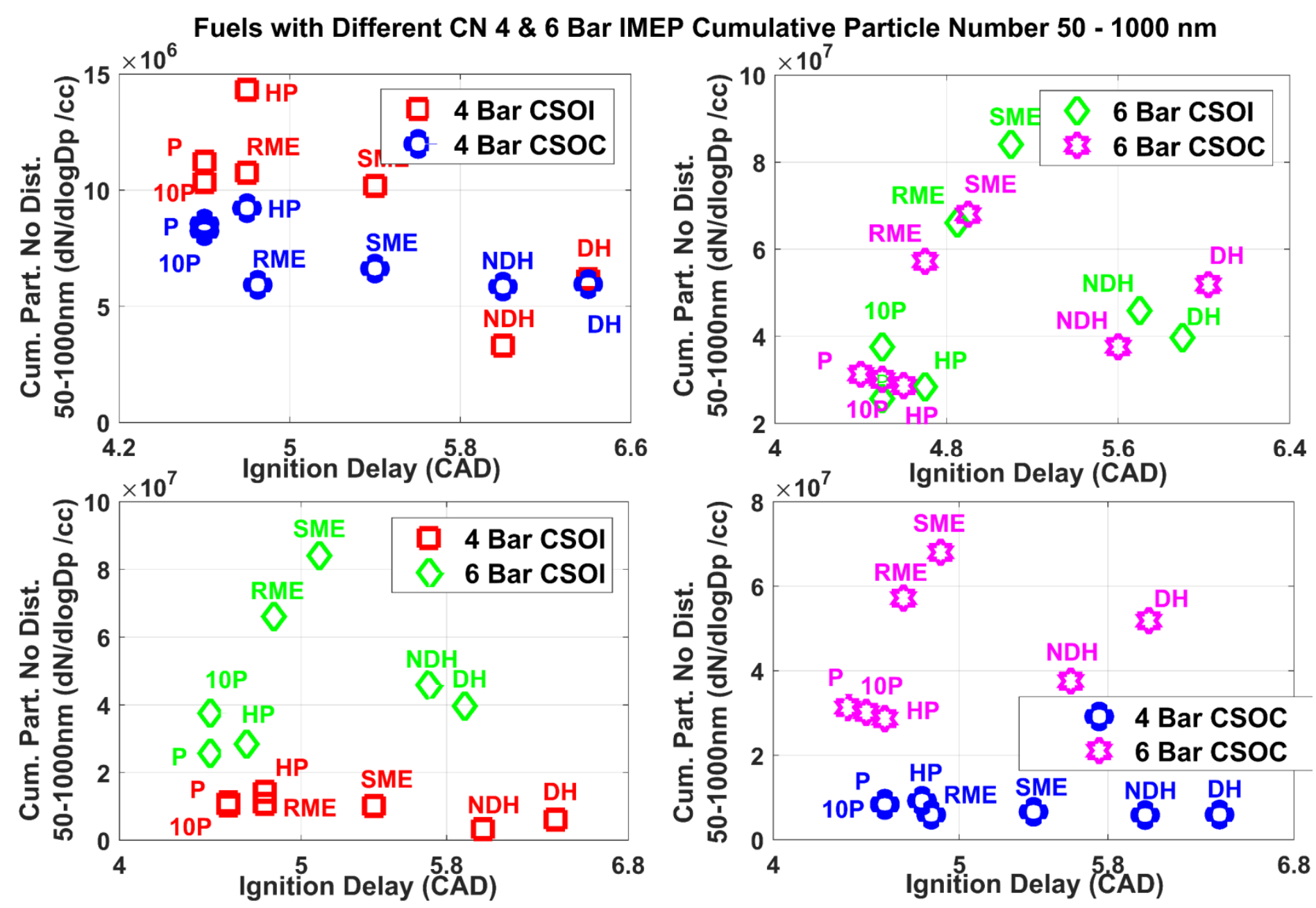

Fig. 18. Effect of ignition delay on particle number in accumulation mode at constant injection (CSOI) and constant combustion (CSOC) timing at 4 bar and 6 bar IMEP for the experimental set of fuels with different $\mathrm{CN}$. 

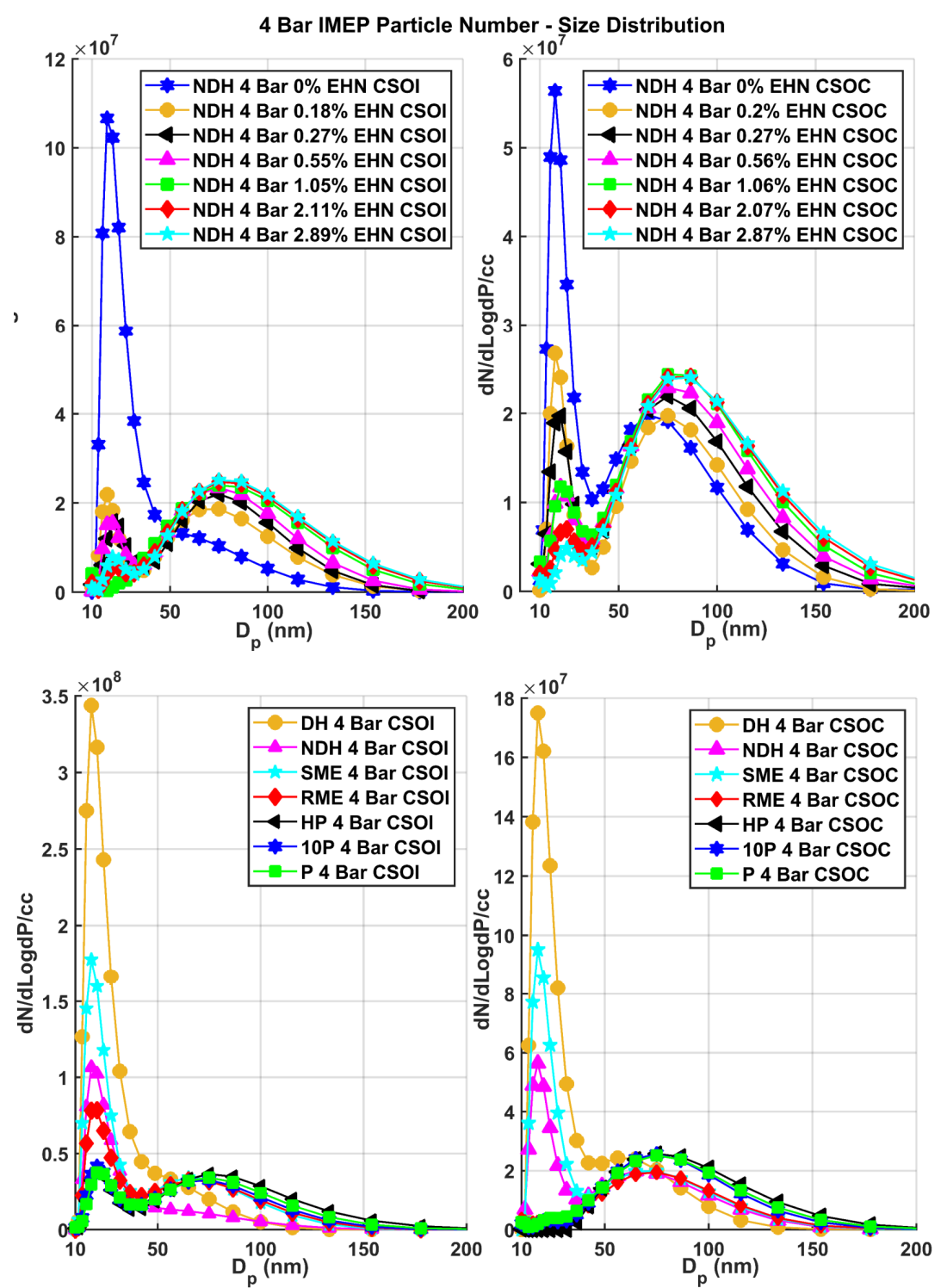

Fig. 19. Particle size characteristic distribution curves for NDH with ignition improver and fuels with different $\mathrm{CN}$ at 4 bar IMEP. 

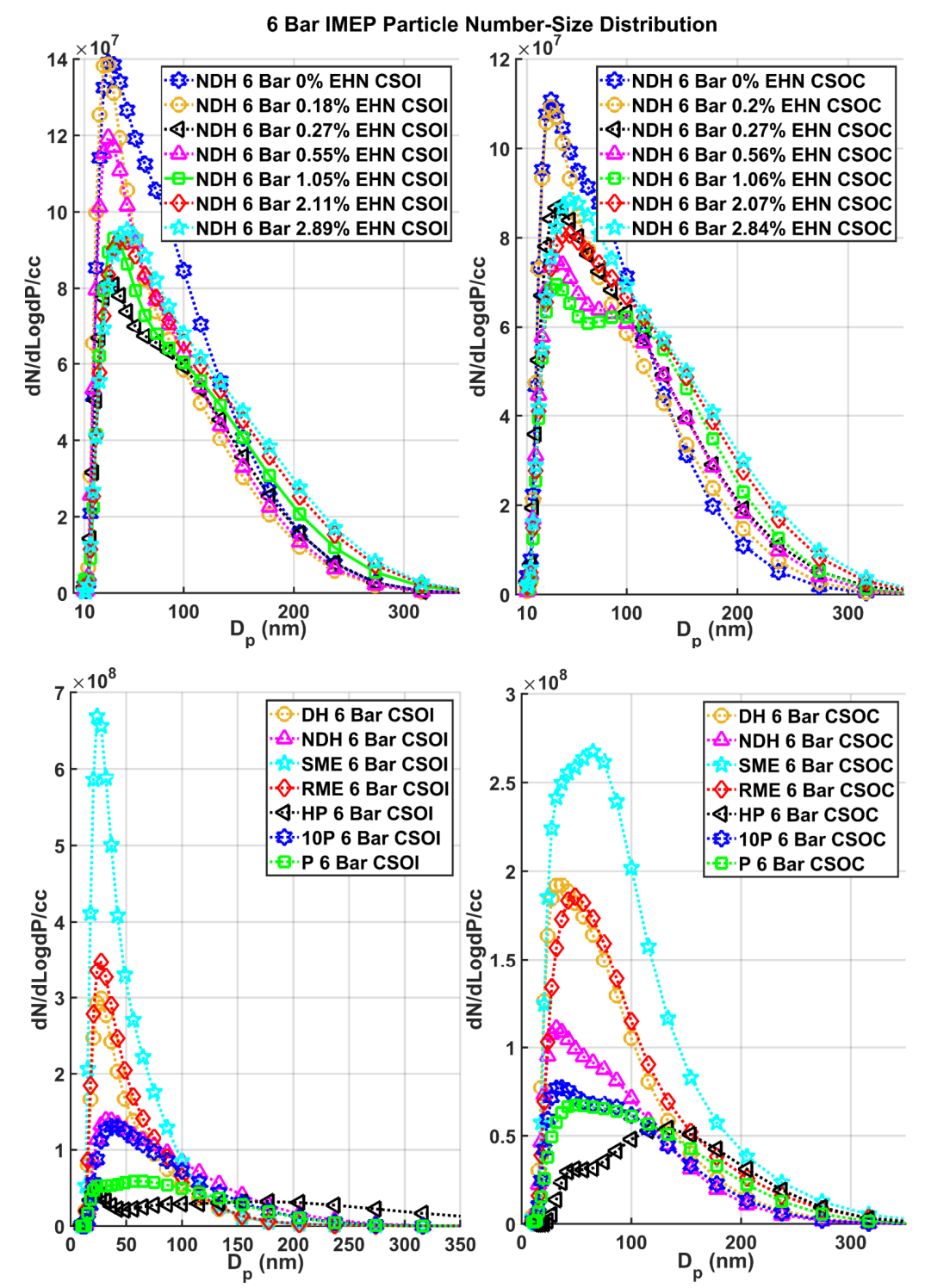

Fig. 20. Particle size characteristic distribution curves for NDH with ignition improver and fuels with different $\mathrm{CN}$ at 6 bar IMEP. 

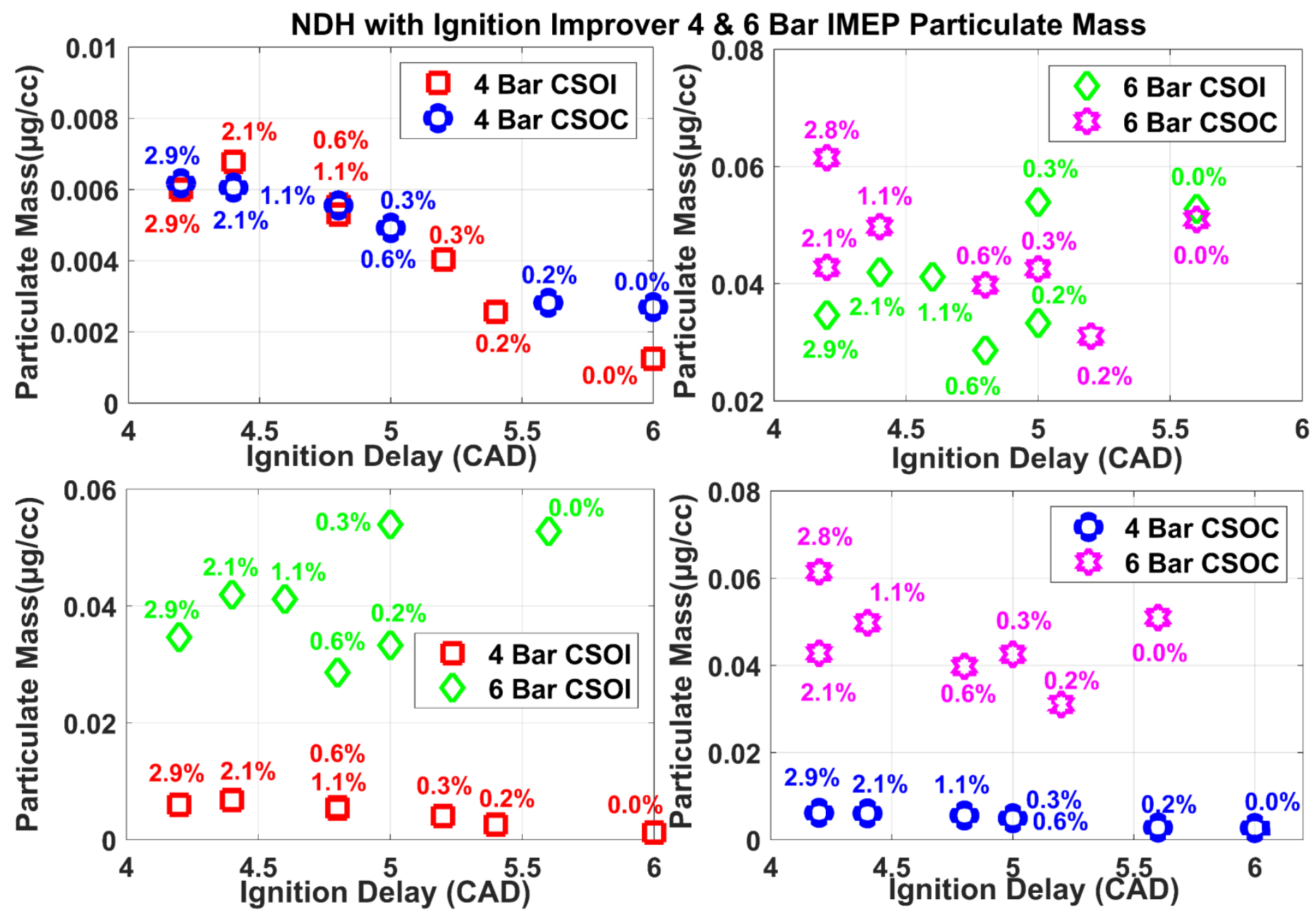

Fig. 21. Ignition delay effect on particulate mass for experimental set of NDH with ignition improver at both timing conditions at 4 bar and 6 bar IMEP. 

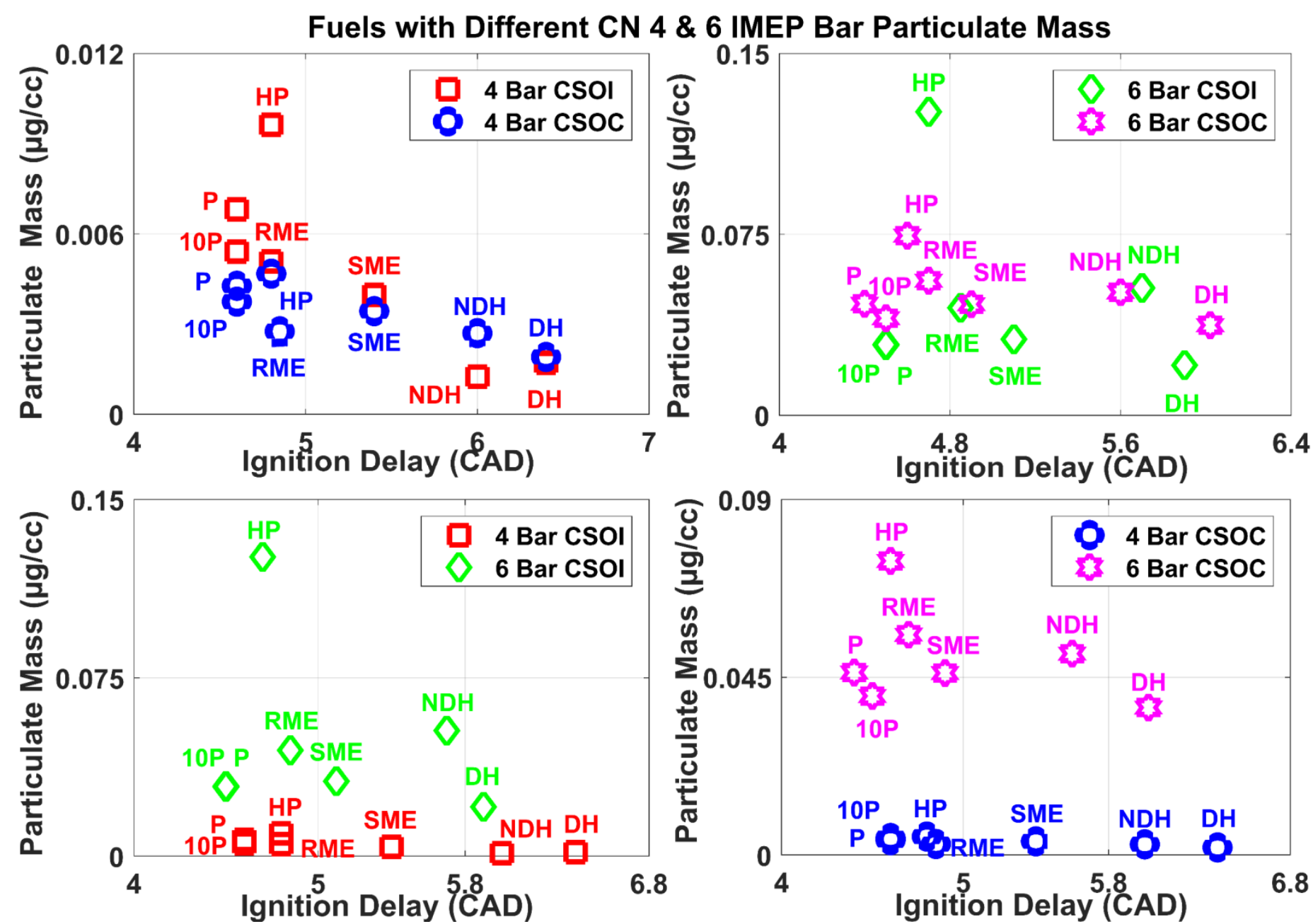

Fig. 22. Ignition delay effect on particulate mass for experimental set of fuels with different $\mathrm{CN}$ at both timing conditions at 4 bar and 6 bar IMEP. 


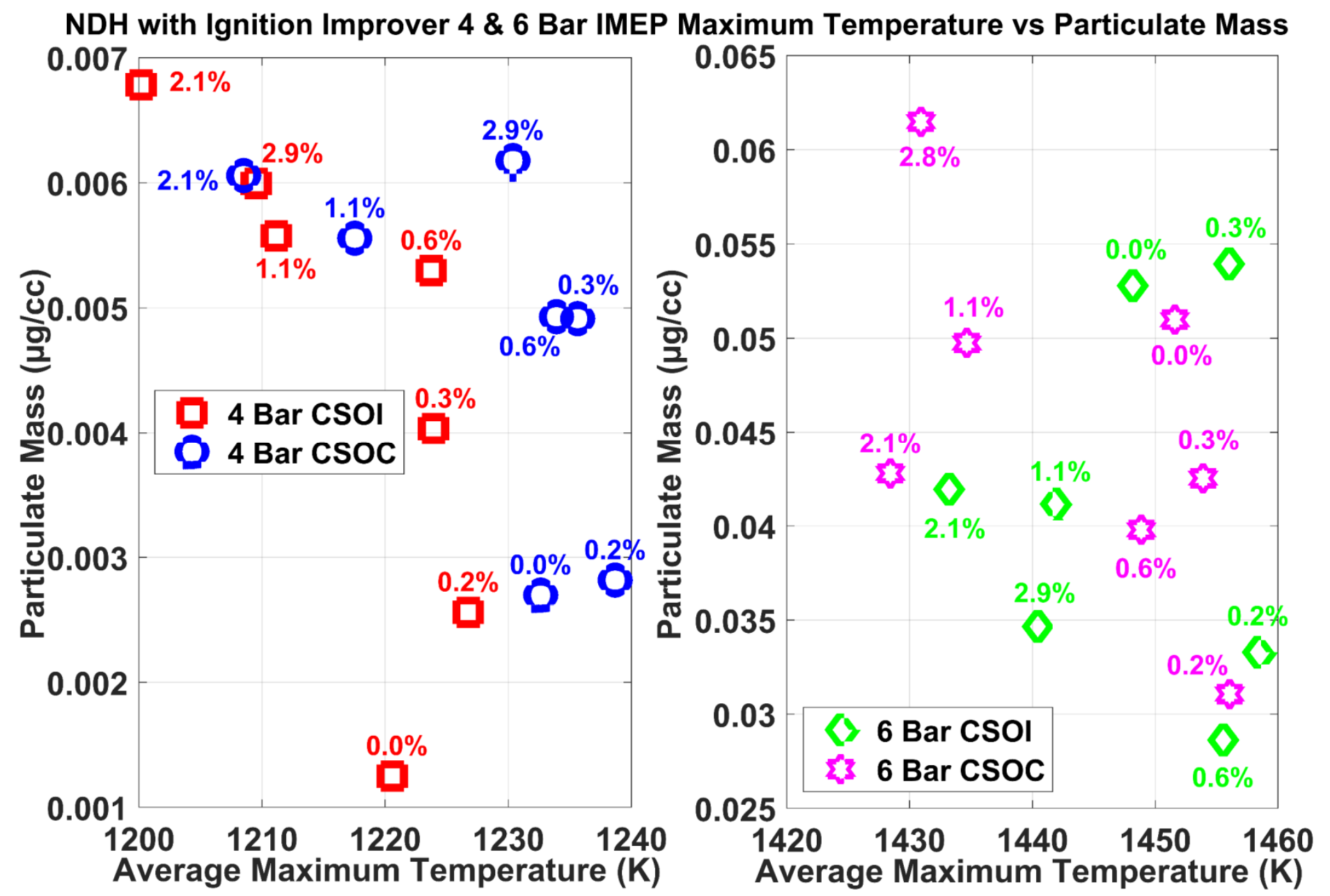

Fig. 23. Effect of maximum in-cylinder temperature on particulate mass at constant injection (CSOI) and constant combustion (CSOC) timing at 4 bar and 6 bar IMEP for the experimental set of $\mathrm{NDH}$ with ignition improver. 


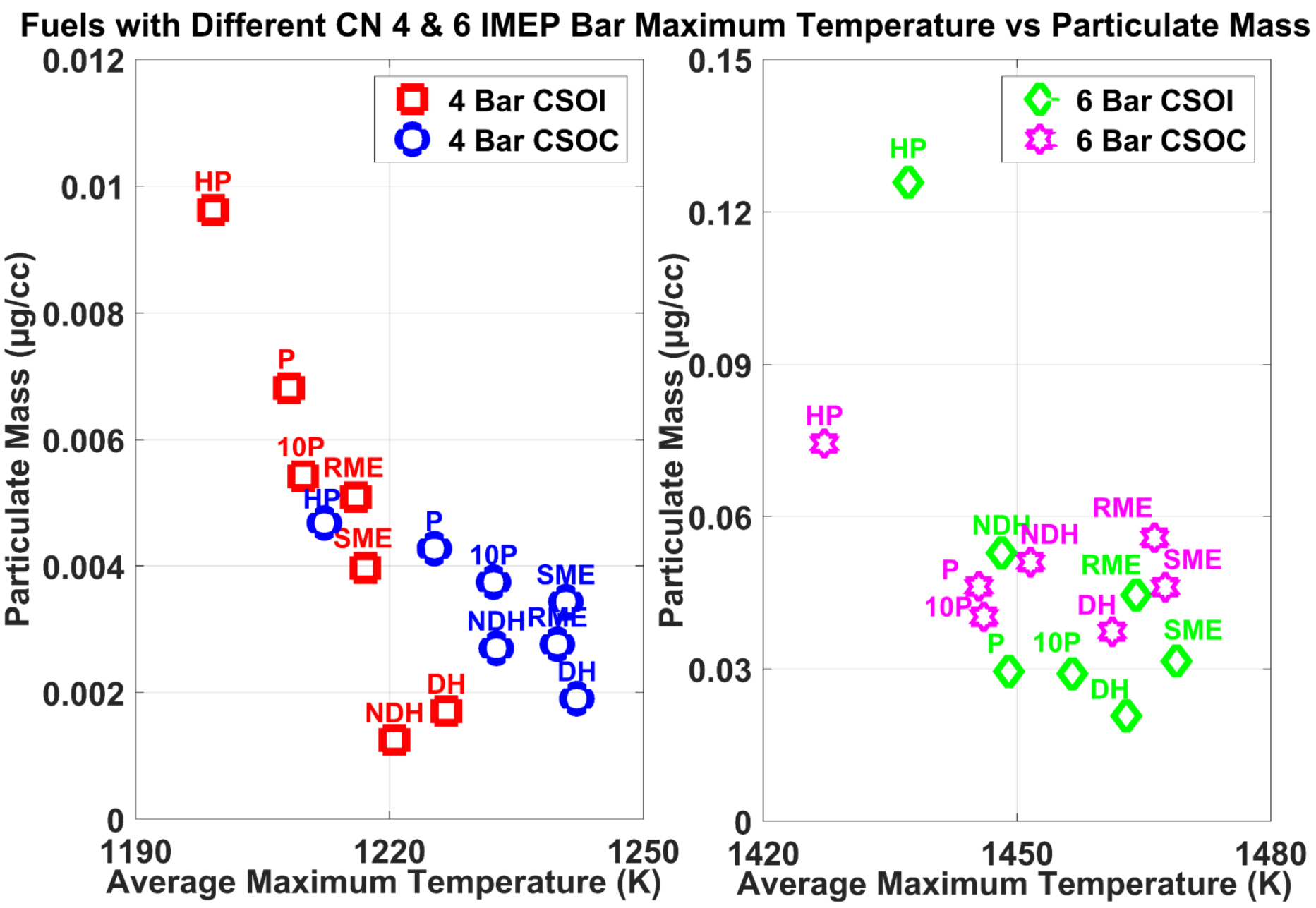

Fig. 24. Effect of maximum in-cylinder temperature on particulate mass at constant injection (CSOI) and constant combustion (CSOC) timing at 4 bar and 6 bar IMEP for the experimental set of fuels with different $\mathrm{CN}$. 